\title{
Of tuberculosis and non-tuberculous mycobacterial infections - a comparative analysis of epidemiology, diagnosis and treatment
}

\author{
Radha Gopalaswamy ${ }^{1}$, Sivakumar Shanmugam ${ }^{1}$, Rajesh Mondal ${ }^{1}$ and Selvakumar Subbian ${ }^{2^{*}}$ (D)
}

\begin{abstract}
Pulmonary diseases due to mycobacteria cause significant morbidity and mortality to human health. In addition to tuberculosis (TB), caused by Mycobacterium tuberculosis (Mtb), recent epidemiological studies have shown the emergence of non-tuberculous mycobacteria (NTM) species in causing lung diseases in humans. Although more than 170 NTM species are present in various environmental niches, only a handful, primarily Mycobacterium avium complex and M. abscessus, have been implicated in pulmonary disease. While TB is transmitted through inhalation of aerosol droplets containing Mtb, generated by patients with symptomatic disease, NTM disease is mostly disseminated through aerosols originated from the environment. However, following inhalation, both Mtb and NTM are phagocytosed by alveolar macrophages in the lungs. Subsequently, various immune cells are recruited from the circulation to the site of infection, which leads to granuloma formation. Although the pathophysiology of TB and NTM diseases share several fundamental cellular and molecular events, the host-susceptibility to Mtb and NTM infections are different. Striking differences also exist in the disease presentation between TB and NTM cases. While NTM disease is primarily associated with bronchiectasis, this condition is rarely a predisposing factor for TB. Similarly, in Human Immunodeficiency Virus (HIV)-infected individuals, NTM disease presents as disseminated, extrapulmonary form rather than as a miliary, pulmonary disease, which is seen in Mtb infection. The diagnostic modalities for TB, including molecular diagnosis and drug-susceptibility testing (DST), are more advanced and possess a higher rate of sensitivity and specificity, compared to the tools available for NTM infections. In general, drugsensitive TB is effectively treated with a standard multi-drug regimen containing well-defined first- and second-line antibiotics. However, the treatment of drug-resistant TB requires the additional, newer class of antibiotics in combination with or without the first and second-line drugs. In contrast, the NTM species display significant heterogeneity in their susceptibility to standard anti-TB drugs. Thus, the treatment for NTM diseases usually involves the use of macrolides and injectable aminoglycosides. Although well-established international guidelines are available, treatment of NTM disease is mostly empirical and not entirely (Continued on next page)
\end{abstract}

\footnotetext{
* Correspondence: subbiase@njms.rutgers.edu

${ }^{2}$ Public Health Research Institute, New Jersey Medical School, Rutgers, The State University of New Jersey, Newark, NJ, United States

Full list of author information is available at the end of the article
}

(c) The Author(s). 2020 Open Access This article is licensed under a Creative Commons Attribution 4.0 International License, which permits use, sharing, adaptation, distribution and reproduction in any medium or format, as long as you give appropriate credit to the original author(s) and the source, provide a link to the Creative Commons licence, and indicate if changes were made. The images or other third party material in this article are included in the article's Creative Commons licence, unless indicated otherwise in a credit line to the material. If material is not included in the article's Creative Commons licence and your intended use is not permitted by statutory regulation or exceeds the permitted use, you will need to obtain permission directly from the copyright holder. To view a copy of this licence, visit http://creativecommons.org/licenses/by/4.0/ The Creative Commons Public Domain Dedication waiver (http://creativecommons.org/publicdomain/zero/1.0/) applies to the data made available in this article, unless otherwise stated in a credit line to the data. 


\begin{abstract}
(Continued from previous page)
successful. In general, the treatment duration is much longer for NTM diseases, compared to TB, and

resection surgery of affected organ(s) is part of treatment for patients with NTM diseases that do not

respond to the antibiotics treatment. Here, we discuss the epidemiology, diagnosis, and treatment modalities available for TB and NTM diseases of humans.
\end{abstract}

Keywords: Mycobacterium tuberculosis, Non-tuberculous mycobacteria, Lung disease, Molecular diagnosis, Drug sensitivity test, Antitubercular drugs, Macrolides

\section{Background}

Tuberculosis (TB), caused by Mycobacterium tuberculosis (Mtb), is a leading killer among the infectious disease of humans that mainly affects the lungs [1]. Pathologically, TB is characterized as necrotizing granulomatous inflammation of infected organs [2]. Dissemination of Mtb infection in the population occurs mainly by inhalation of contaminated aerosols from patients with active pulmonary disease. In humans, exposure to Mtb can lead to either primary active disease or asymptomatic latent infection (LTBI) [3]. The LTBI accounts for about a third- to -quarter of the global population. These individuals are capable of reactivating to symptomatic TB upon host immune-suppressing conditions. The risk for LTBI cases to develop active TB is about 5\% in the first 18 months of infection, after which the relapse rate reduces to nearly $5 \%$ for the lifetime [4].

The family of non-tuberculous mycobacteria (NTM) consists of about 170 species of mycobacteria. However, pulmonary diseases in humans are mostly caused by species of $M$. avium complex (MAC), M. kansasii, and M. abscessus [5]. Human infections due to NTM are primarily acquired from the environment, although the precise mode of transmission remains unclear. In addition to pulmonary involvement, lymphatic, skin, and soft tissues are also frequently affected by NTM infections [6]. Further, underlying health conditions, such as chronic obstructive pulmonary disease (COPD), pneumoconiosis, bronchiectasis, previous history of $\mathrm{TB}$, post-radiotherapy fibrosis, chronic pulmonary aspiration, cystic fibrosis (CF), immune deficiency, HIV infection, alcoholism, cancer, and diabetes mellitus (DM) pose a significant risk for NTM infections [7].

In clinical specimens, differential diagnosis of Mtb and NTM species is a significant challenge and often misleading since both Mtb and NTMs show positivity to the conventional smear acid-fast staining method. Thus, the incidence of NTM has been underestimated in many TB-endemic countries.

The standard antibiotic regimen for the treatment of drug-sensitive TB contains isoniazid (INH), rifampicin (RIF), pyrazinamide (PZA), and ethambutol (ETH), administered for a minimum of 6 months. However, treatment of multi- and extremely-drug resistant (MDR and XDR) TB cases need additional antibiotics for a prolonged duration. With the availability of newer classes of drugs, such as bedaquiline and delamanid, novel regimens with shorter treatment periods are available to treat MDR-TB cases $[8,9]$. In contrast, NTM diseases do not respond to anti-TB drugs [10]. Treatment of NTM diseases follows specific guidelines, based on the nature of infecting bacteria, and requires species identification. Unlike TB, the treatment for NTM disease takes at least 18 months, with 12 months sputum-negative period [6].

In both TB and NTM pulmonary diseases, the bacterial characteristics and the host factors influence the susceptibility and manifestations of infection as well as the outcome of treatment [11, 12]. Our understanding of the epidemiology, risk factors, and pathophysiology of pulmonary TB in humans has significantly improved over the past 50 years. However, these areas are underdeveloped for NTM diseases. Similarly, more diagnostic and treatment options are available for TB management, compared to NTM diseases. Nonetheless, promising new diagnostic methods and treatment modalities for all forms of TB and NTM disease are in the development pipeline. In this review, we evaluate the progress made in the areas of Mtb and NTM infections of humans, assessing mainly on the epidemiology, diagnosis, and treatment (Table 1).

\section{Main Text \\ Epidemiology and transmission of TB and NTM Epidemiology of drug-sensitive and drug-resistant TB} In 2018, about 1.5 million people died from TB, and nearly 10 million people fall ill with Mtb infection worldwide, of which only 6.4 million were diagnosed and officially reported. The extent of TB burden is higher in males (57\%) than in females (32\%). Globally, an estimated 1.7 billion people are latently infected with Mtb (LTBI) without obvious disease symptoms. Individuals with LTBI mostly develop active disease in the first 12 to 18 months, although reactivation can occur even decades after initial infection [1].

The incidence of global MDR/rifampicin-resistant (RR)-TB in 2018 was estimated to be $3.4 \%$ for new cases and $18 \%$ among previously treated cases, while the proportion of XDR-TB cases among MDR-TB cases was 
Table 1 Summary of key features of pulmonary TB and NTM diseases

\begin{tabular}{|c|c|c|c|}
\hline Category & Tuberculosis (TB) & $\begin{array}{l}\text { Pulmonary Non-tuberculous mycobacteria } \\
\text { (NTM) infections }\end{array}$ & References \\
\hline 1. Causative agent & M. tuberculosis complex organisms & $\begin{array}{l}\text { M. avium complex. M. abscessus, M. kansasii, } \\
\text { M. malmoense, M. xenopi }\end{array}$ & {$[2,5,6]$} \\
\hline 2. Mode of transmission & $\begin{array}{l}\text { Inhalation of contaminated aerosols } \\
\text { from patients with pulmonary TB }\end{array}$ & $\begin{array}{l}\text { Primarily acquired from the environment - } \\
\text { lack of person-to-person transmission }\end{array}$ & {$[3,6]$} \\
\hline $\begin{array}{l}\text { 3. Sex with higher } \\
\text { disease burden }\end{array}$ & Male & Female & {$[1,13]$} \\
\hline $\begin{array}{l}\text { 4. Predisposition/ } \\
\text { Co-morbidities }\end{array}$ & HIV, DM, Immunosuppression & $\begin{array}{l}\text { Bronchiectasis, Previous history of TB, CF, } \\
\text { COPD }\end{array}$ & {$[1,14-21]$} \\
\hline \multicolumn{4}{|l|}{ 5. Diagnosis } \\
\hline 5.1 Clinical & $\begin{array}{l}\text { Lung involvement, alveolar infiltration, } \\
\text { cavitation, } \\
\text { lymphadenopathy and pleural effusion }\end{array}$ & $\begin{array}{l}\text { Nodular or cavitary opacities on chest } \\
\text { radiograph, or an HRCT scan that shows } \\
\text { multifocal bronchiectasis with multiple } \\
\text { small nodules }\end{array}$ & {$[6,22]$} \\
\hline 5.2 Radiological & $\mathrm{X}$-ray; rarely $\mathrm{CT}$ & X-ray; PET/CT or HRCT & {$[6,22]$} \\
\hline $\begin{array}{l}\text { Samples for the } \\
\text { diagnostic test }\end{array}$ & $\begin{array}{l}\text { Sputum samples, bronchial or } \\
\text { bronchioalveolar lavage aspirates, or } \\
\text { tracheal aspirates; Gastric aspirate }\end{array}$ & $\begin{array}{l}\text { Sputum, bronchial wash, or lavage; Gastric } \\
\text { aspirate not preferred due to failure to } \\
\text { indicate active pNTM disease }\end{array}$ & {$[22,23]$} \\
\hline \multicolumn{4}{|l|}{5.3 Microbiological test } \\
\hline 5.3.1 Staining & Acid fast staining; Ziehl Neelson staining & Acid fast staining; Ziehl Neelson staining & [22-24] \\
\hline 5.3.2 Culture & $\begin{array}{l}\text { Solid, Liquid - MGIT } 960 \text { system; the } \\
\text { VersaTREK system; MB/BacT Alert 3D }\end{array}$ & $\begin{array}{l}\text { Solid or liquid including MGIT but } \\
\text { with PNB }\end{array}$ & {$[23,25,26]$} \\
\hline $\begin{array}{l}5.4 \text { Molecular } \\
\text { biological test }\end{array}$ & $\begin{array}{l}\text { TB Ag MPT64 RAPID } \\
\text { Nucleic acid amplification test } \\
\text { (NAAT) - } \\
\text { Amplified Mycobacterium tuberculosis } \\
\text { direct (MTD); Amplicor Mycobacterium } \\
\text { tuberculosis Test; } \\
\text { Xpert MTB-Rif system; } \\
\text { Xpert MTB-Rif Ultra } \\
\text { Loop-mediated isothermal amplification } \\
\text { (LAMP)-based MTB detection system; } \\
\text { Cross-priming amplification (CPA)-based } \\
\text { TB diagnostic system; } \\
\text { CE-IVD Genedrive; } \\
\text { Anyplex II MTB/MDR and MTB/XDR; } \\
\text { Anyplex MTB/NTM MDR-TB kit; } \\
\text { EZplex MTBC/NTM; } \\
\text { VereMTB Detection Kit } \\
\text { Line probe assays (LiPA) - } \\
\text { Inno-LiPA Mycobacteria assay; } \\
\text { Genotype Mycobacterium CM and AS } \\
\text { assays } \\
\text { Others - } \\
\text { MALDI-TOF } \\
\text { Next gen sequencing } \\
\text { For Latent TB - } \\
\text { Tuberculin skin test } \\
\text { IGRA test - QuantiFERON-TB Gold, } \\
\text { QFT-GIT, QFT-Plus and T-SPOT.TB }\end{array}$ & $\begin{array}{l}\text { TB Ag MPT64 RAPID - to differentiate } \\
\text { M. tb complex from NTM } \\
\text { HPLC } \\
\text { PCR-RFLP ; PCR sequencing } \\
\text { NAATs - } \\
\text { Accuprobe analysis } \\
\text { Anyplex MTB/NTM MDR-TB } \\
\text { EZplex MTBC/NTM; } \\
\text { Genedia MTB/NTM Detection Kit } \\
\text { LiPAs - } \\
\text { Inno-LiPA Mycobacteria assay; } \\
\text { GenoType Mycobacterium CM -AS } \\
\text { Others - } \\
\text { MALDI-TOF } \\
\text { Next gen sequencing }\end{array}$ & $\begin{array}{l}\text { MPT64 - }[27,28] \\
\text { HPLC - }[29,30] \\
\text { PCR-RFLP/Sequencing } \\
\text { [31-34] } \\
\text { NAAT - } \\
\text { [35-53] } \\
\text { LIPA - } \\
{[49,54-58]} \\
\text { Others - } \\
\text { [59-66] } \\
\text { LTBI - } \\
\text { [67-70] }\end{array}$ \\
\hline
\end{tabular}

estimated at $6.2 \%$ [1]. Most of the drug-sensitive, MDR, and XDR cases are reported in Asian countries, including India and China. Inappropriate clinical use of anti-TB drugs and poor patient compliance, associated with prolonged multi-drug treatment, contributes to the emergence of drug resistant-Mtb strains [71]. Also, molecular epidemiological data suggest that transmission of MDR- and XDR- Mtb strains in the community is the dominant mode of spread in many TB-endemic countries [14].

Thus, a clear understanding of Mtb transmission and acquisition of new infection is essential for guiding effective TB control strategies [72]. Similar to drug-sensitive TB cases, there is a dire necessity to improve the diagnosis and treatment strategies for MDR- and XDR-TB cases, which is 
one of the main goals of the END-TB policy developed by the WHO [73].

\section{Epidemiology of NTM diseases}

The human infections due to NTM were earlier believed to be acquired mainly from contaminated environmental sources through aerosols; however, recent reports indicate person-to-person transmission as well [74, 75]. Several clinical reports of NTM cases revealed similarities in disease symptoms caused by NTM and TB [76, 77]. A study on population genomics shows that genetically clustered NTM organisms caused the majority of infections worldwide. This study has also revealed the recent emergence of dominant clones of $M$. abscessus that have spread between continents [74]. The incidence and prevalence of NTM cases and the strain distribution are highly variable across different geographical locations. A global survey of NTM species isolated from human specimens found that about one-half of them belongs to the M. avium complex (MAC). However, the relative frequency of MAC varies widely by geographical region - 31\% of isolates from South America, 52\% from North America, and 71\% from Australia [78]. In a clinical study conducted among CF patients with NTM infection, MAC was isolated in $61 \%, M$. abscessus in $39 \%$, and other NTM in $21 \%$ of cases in at least one specimen. About 19\% of these patients had multiple NTM species isolated [79]. Despite the heterogeneous distribution of NTM species worldwide, causing a spectrum of diseases, pulmonary NTM infections constitute a substantial, often unappreciated, burden of illness in humans [80]. Further, pulmonary NTM infections can occur without any co-existing chronic diseases, such as CF. A report by Marras et al. shows that the prevalence rate of NTM cases has increased in North America from 9.1 to 14.1 per 100,000 persons/year between 1997 and 2003 [81]. Interestingly previous studies had observed a reduction in the number of pulmonary NTM and TB cases in several countries after the implementation of national BCG vaccination policy. This suggests that BCG confers cross-protection against NTM, and in countries without a nationwide BCG immunization program, a rise in NTM cases is expected [82-85].

Importantly, unlike $\mathrm{TB}$, pulmonary NTM infections are more prevalent in women (59\%) and the elderly (median age 66) than younger men, with MAC being the most common NTM species [13]. Prevots et al., reported an increase in the prevalence of pulmonary NTM cases among individuals over 60 years, from 19.6 cases/ 100,000 person-years between 1994 and 1996 to 26.7 cases/100,000 person-years between 2004 and 2006. In this study, MAC was the most common species isolated in patients with definitive disease (80.1\%) followed by $M$. chelonae and M. abscessus (12.1\%), M. fortuitum (5.6\%), and M. kansasii (5.5\%) [86]. Similarly, an epidemiological study on the prevalence of pulmonary NTM diseases in Australia has found an increase in pulmonary NTM cases from 5.5 to $10.2 / 100,000$ people over the six years (1999 to 2005), with the highest number of cases among people aged $>60$ years and predominantly women [87]. Further, the prevalence of pulmonary NTM diseases increased from 1.3 to 7.9 cases/100,000 population in Asia, most of which were due to MAC and M. abscessus $[87,88]$. Moreover, in Europe, the prevalence of NTM cases has increased from 0.9 to $2.9 / 100,000$ persons from 1995 to 2006, respectively [89]. Together, these studies indicate a growing trend in the incidence and prevalence of pulmonary NTM cases worldwide, in association with a range of underlying health conditions, such as immunosuppression, age, sex, and previous history of lung diseases.

\section{TB among HIV and Diabetes Mellitus cases}

Among HIV-infected individuals, TB is one of the most frequent opportunistic infectious diseases. The risk of developing TB is 26 times higher in people with HIV infection, compared to the non-HIV population [20]. This increased risk is due to the weakening of the immune system by HIV infection. The risk of developing TB is about $7 \%$ to $10 \%$ each year among HIV-positive individuals. In contrast, the risk of developing TB is $10 \%$ over a lifetime for people without HIV infection [14]. An estimated $8.6 \%$ (range, $7.4-10 \%$ ) of the incident TB cases in 2018 were among people living with HIV infection [1].

Type 2 diabetes mellitus (DM) is another serious risk factor and critical co-morbid condition that significantly elevates the mortality due to TB worldwide [17]. Besides, the onset of DM aggravates the disease severity of $\mathrm{TB}$ cases and muddles with the response to treatment. Further, DM patients have a faster disease progression following Mtb infection, and they respond poorly to treatment [90-92]. Despite the increasing evidence on the profound impact of DM co-morbidity on TB treatment outcomes, data on TB-DM co-existence is missing in new TB drug clinical trials. Therefore, the inclusion of TB-DM co-morbidity should receive a higher priority in prospective randomized clinical TB drug efficacy trials, with specific emphasis on differential outcomes of treatment among TB-DM patients [18].

\section{NTM diseases in HIV and Diabetes Mellitus cases}

NTM infections do not present with the same clinical symptoms in patients with HIV/AIDS compared to "stand-alone" infections in otherwise healthy individuals. Besides, the possibility of overlooking NTMs in these patients is significant, since TB would be the first consideration among HIV-positive cases that show symptoms of pulmonary mycobacterial disease [15]. 
Both primary and secondary NTM infections can affect the respiratory system in humans. Unlike TB, a localized NTM pulmonary disease is rare in patients with HIV coinfection; instead, these cases typically display a disseminated form of the disease [19].

Although DM confers susceptibility to TB, the association between NTM infections and DM remains unclear. Few studies have indicated DM as a co-morbid condition in soft tissue and pulmonary NTM infections during baseline studies $[16,21,93]$. Thus, our understanding of the impact of DM on host immunity and disease progression during NTM infections needs to be significantly improved, and this should be an active area of future research.

\section{Diagnosis of TB and NTM diseases Microbiological Diagnosis of TB}

In general, diagnosis of pulmonary $\mathrm{TB}$ is suspected in patients with relevant clinical manifestations, such as persistent and productive cough, hemoptysis, fever, weight loss, and previous history of TB. The clinical observations of pulmonary TB can also be confirmed by chest X-ray findings, which is a routine practice in many TB-endemic countries [94]. In the X-ray of a patient with active pulmonary $\mathrm{TB}$, alveolar infiltration, cavitation, lymphadenopathy, and pleural effusion are usually observed [22]. For pulmonary TB, the most prevalent form of the disease, the primary specimens are sputum samples, bronchial or bronchioalveolar lavage aspirates, or tracheal aspirates [68]. In TB-endemic countries, "Acid-fast bacilli (AFB) staining" or Ziehl-Neelsen staining procedure is the standard method of Mtb detection in sputum specimens [24]. The AFB staining has a sensitivity of up to $70 \%$ in the sputum specimen of patients with cavitary TB [68]. Thus, the AFB smear microscopy, although rapid and inexpensive, has limited sensitivity due to false positives, such as the presence of NTM in the samples [95]. Culturing the bacteria in liquid or solid media is the "gold" reference standard for TB diagnosis, since this method performs better than AFB staining, and is cost-effective in resource-poor countries [68]. While the AFB smear microscopy takes 12- 24 hours, the culture methods need 2--6 weeks to produce diagnostic results for TB.

There are three FDA-approved commercial diagnostic platforms available for the semi-automated, broth-based culture of mycobacteria: the Mycobacteria Growth Indicator Tube (MGIT) 960 system, the VersaTREK system, and the MB/BacT Alert 3D. These are an improvised version of conventional culture methods to detect Mtb; these methodologies take an average of 10 days for stable bacterial growth [25]. With these methods, the overall sensitivity of culture-confirmed TB cases can be increased from $91 \%$ with one sputum specimen to $98 \%$ and $100 \%$ with second and third sputum specimens, respectively. In TB-endemic countries, both solid and liquid culture methods are recommended with or without adjunct AFB smear microscopy $[96,97]$.

\section{Microbiological Diagnosis of NTM diseases}

In contrast to TB, diagnosis of NTM is very challenging due to exposure of individuals to the environment, and it is necessary to differentiate NTM isolate from an individual, as a commensal/colonizer, versus a causal agent of the disease. In fact, colonization of NTM species has been reported in many suspected NTM cases without any pulmonary disease symptoms. This observation highlights the ambiguity about whether a low-grade NTM infection or disease exists or if the specimen is contaminated with environmental NTM species [98]. The ATS (American Thoracic Society) and IDSA (Infectious Diseases Society of America) has issued a set of criteria to identify the real pulmonary NTM disease. This classification includes clinical findings, such as lung involvement on chest radiograph or PET/CT scan, microbiological testing, and strain identification, to confirm NTM disease [6].

Compared to TB, the clinical presentation of NTM is heterogeneous and complicated by underlying comorbid conditions, such as DM, COPD, and CF [98]. Clinical symptoms, in combination with the presence of pulmonary nodular or cavitary opacities on the radiograph, or multifocal bronchiectasis, and dispersed multiple small nodules on HRCT scan, are indicative of active NTM disease [6]. Although AFB staining would identify mycobacteria, it would not discriminate NTM from Mtb. Therefore, it is recommended to grow NTM from the clinical specimens, such as sputum, bronchial wash, or lavage on a solid and/or liquid media. Culturing of mycobacteria on growth media is preferred for identifying rapid and slow-growing species and considered as a "gold standard" diagnostic method [23, 99, 100]

Identification of specific NTM species in the clinical specimen is crucial since the treatment regimens differ strikingly among different NTM strains. Various biochemical tests, including niacin accumulation test, arylsulfatase test, nitrate reduction, catalase estimation, and growth in MacConkey agar media, are commonly used for NTM species identification [101]. One of the vital biochemical tests used routinely in clinical laboratories to discriminate Mtb from NTM is the p-nitro benzoic acid test (PNB). In the PNB inhibition test, while the growth of Mtb is inhibited, NTMs grow on culture medium containing PNB, as they are resistant to PNB. The average reporting time for MGIT 960-PNB test is seven days, compared to 28 days for the LJ-PNB test and about one to two months when using the conventional biochemical analysis described above [26]. 


\section{Molecular biological diagnosis of active $T B$}

Since culture- and microscopy-based diagnostic techniques take a longer time to get results, molecular biological methods have emerged as a rapid diagnostic platform for TB. Introduction of the mycobacterial nucleic acid amplification test (NAAT) significantly reduced the turn-around time of clinical diagnosis of $\mathrm{TB}$, compared to the traditional culture and smear methods [102]. The US$\mathrm{CDC}$ and the Association of Public Health Laboratories (APHL) recommend the use of NAAT to diagnose TB in clinical specimens. Several commercial NAAT systems, such as the Amplified Mycobacterium tuberculosis Direct (MTD) test, Xpert MTB-RIFsystem, Amplicor Mycobacterium tuberculosis Test, loop-mediated isothermal amplification (LAMP)-based Mtb detection system, crosspriming amplification (CPA)-based TB diagnostic system and the CE-IVD Genedrive are widely used in clinical laboratories [64]. The MTD method, which is based on the Transcription-Mediated Amplification (TMA) and the Hybridization Protection Assay (HPA), qualitatively detects ribosomal ribonucleic acid (rRNA) from Mtb complex organisms within 2.5 to 3.5 hours [38]. Although the MTD test is helpful in rapid and reliable detection of Mtb, this test cannot ascertain drug susceptibility of the Mtb strain in the specimen [103]. The Amplicor Mtb Test is another PCR-based diagnostic tool for the direct detection of Mtb complex organisms [35]. Both MTD and Amplicor are Food and Drug Administration (FDA) approved NAAT systems for testing smear-positive TB cases [64]. In contrast, the Xpert MTB/RIF system is specific to TB diagnosis, designed for the GeneXpert platform, to detect drug-sensitive as well as RR- Mtb strains directly from the sputum sample. This assay is based on a nested real-time PCR amplifying the $r p o B$ gene of Mtb, which is the most prominent target for rifampicin resistance, with high sensitivity (>90\%), and results can be obtained within 2 hours $[41,50]$. The Xpert MTB/RIF Ultra was developed to overcome the drawback of identifying Mtb in paucibacillary TB cases, and is recommended by the $\mathrm{WHO}[51,53]$. The LAMP-MTBC detection kit, which is endorsed by the WHO, targets the gyrB gene and IS regions of the Mtb complex genome. In this assay, the amplified product is visualized with the naked eye or under ultraviolet (UV) light [47]. In the CPA-based TB diagnostic system, PCR amplification is done at a single temperature using multiple primers and probes of Mtb. The amplified products are detected on a lateral flow strip placed in an enclosed, sealed plastic device $[39,52]$. The CE-IVD is a rapid molecular TB detection test designed with paper-based DNA extraction method, coupled with PCR amplification to detect a short repetitive region, rep13E12, and a segment of the $r p o B$ gene of Mtb. Detection of reaction products requires the Epistem's Genedrive instrument, a portable, bench-top platform with real-time PCR and melting temperature analysis capabilities. However, this assay showed low sensitivity to MAC and cross-reacts with three other mycobacterial species, including $M$. abscessus, M. gordonae, and M. thermoresistibile [36, 46].

Apart from Xpert MTB.-RIF, newer kits are available to diagnose MDR- and XDR- TB cases. The Anyplex II MTB/ $\mathrm{MDR}$ and MTB/XDR are designed to detect resistance mutations in the Mtb genome, including rpoB (RIF), katG, and $\operatorname{inh} A$ (INH), gyrA (fluoroquinolones), and rrs and eis (aminoglycosides) $[40,44]$. Further, the Anyplex MTB/NTM MDR-TB kit has also been evaluated to detect Mtb complex and NTM species, as well as their drug susceptibility to RIF (rpoB) and INH (katG and inhA) [45]. The EZplex MTBC/NTM is a Real-Time PCR kit used to detect Mtb complex and NTMs. This assay has an overall sensitivity and specificity of $98.6 \%-100 \%$ for the detection of Mtb [42]. The VereMTB Detection Kit is a NAAT based Lab-onChip (LoC) assay used for the detection and identification of Mtb complex, NTMs, and the diagnosis of MDR-TB. This kit targets IS6110 and 16srRNA sequences to differentiate Mtb from NTM. Further, the LoC kit can be used on direct sputum samples to perform DST, to identify resistance mutations in rpoB (RIF) and katG/inhA (INH). This kit has a sensitivity and specificity of $97.0 \%$ and $98.3 \%$ for the detection of the Mtb complex [43].

The Line probe assays (LiPA) are another molecular technique that makes use of hybridization-based probes for the identification of mycobacteria from samples [58]. The LiPA utilizes nitrocellulose membrane strips embedded with genus- and species-specific probes. The turn-around time of the LiPA method is approximately six hours, including a preliminary PCR amplification [58]. There are three commercial LiPA kits available the Inno-LiPA Mycobacteria assay, the Genotype Mycobacterium CM, and AS assays. These assays target the 16S-23S rDNA spacer region and the 23S rDNA for the identification of mycobacteria [33]. The Inno-LiPA Mycobacteria is a reverse-hybridization, DNA probe assay platform, designed to identify up to 17 different taxa simultaneously, with a sensitivity of $99.6 \%$. The Genotype MTBC is another commercially available DNA strip assay used to differentiate members of the Mtb complex organisms and the identification of $M$. bovis BCG. Further, this method can be performed directly on liquid cultures of mycobacteria from primary isolations without the need for further cultivation on solid media [55].

Whole genome sequencing (WGS) is an alternate option to identify and characterize various mycobacterial species; however, it incurs a higher cost and is not suitable for routine diagnostic screening of samples in endemic countries. There are first and second-generation (next-gen) sequencing (NGS) methods that help to detect mutations, polymorphisms that are responsible for drug 
resistance in Mtb [64]. Previously, the need for extraction of DNA from cultured samples discouraged the use of sequencing as a routine diagnostic test [65]. However, with the development of a system to use the patients' sputum samples directly, NGS is evolving as a popular direct-diagnostic tool for TB diagnosis [59, 63, 65, 66].

The Matrix-Assisted Laser Desorption IonizationTime Of Flight (MALDI-TOF) technology, in conjunction with mass spectrometry (MS), is another method for the identification and differentiation of mycobacteria. This method has $98.6 \%$ specificity and takes approximately $1-2 \mathrm{~h}$ to generate results from samples and is highly cost-effective [62].

\section{Diagnosis of LTBI}

Unlike the diagnosis of active TB, only a few methods are in use to diagnose LTBI cases. These are individuals with immunological evidence of exposure to Mtb or its antigens but without symptomatic clinical disease. Two commonly used screening tests for LTBI are the tuberculin skin test (TST) and the Interferon-gamma release assay (IGRA). The conventional TST involves an intradermal injection of purified protein derivative (PPD), followed by an examination of the induration after $48-72$ hours [67]. Individuals previously exposed to Mtb and/or its antigens are sensitized to PPD and produce cytokines at the site of injection that causes a delayed-type hypersensitivity reaction. Conventionally, an induration of $>10 \mathrm{~mm}$ to PPD-injection, is considered a positive response in individuals without HIV or other co-existing health conditions. However, BCG vaccinated individuals can also show a hypersensitivity reaction, making the TST as a non-specific screening test [67].

The IGRA is used for LTBI screening of BCG vaccinated individuals and those of $>5$ years of age, with a low or moderate risk of developing the active disease [68]. Currently, two types of IGRAs are available: QuantiFERON-TB Gold In-tube Test (QFT-GIT) and T-SPOT.TB. These assays use Mtb-specific antigens and measures the host immune cell response (i.e., production of interferon-gamma; IFNg); however, they differ technically and their target readout [67]. While the T-SPOT.TB is an ELISPOT assay that uses peripheral blood mononuclear cells (PBMCs) isolated from the whole blood; the QFT-GIT is an ELISA-based test for measuring IFNg secreted by PBMC upon Mtb antigen stimulation. The QFT-GIT tubes are precoated with a single cocktail of peptides from Mtb proteins, such as ESAT-6, CFP-10, and TB7.7 [69]. The QFT-GIT IGRA received US-FDA clearance in 2017. An improvised version of QFT-GIT, namely QFT-Plus-IGRA, provides a diagnostic advantage over the previous version, mainly to diagnose cases with $\mathrm{CD}^{+}{ }^{+} \mathrm{T}$-cell-reliant diseases, such as HIV-TB. However, this assay is not cost-effective and needs further evaluation to use in TB-endemic countries [70].

\section{Drug susceptibility testing for $T B$}

A critical feature of TB diagnosis is identifying the drug susceptibility of Mtb to the first and second-line antibiotics rapidly and accurately for efficient treatment. While MDR-TB cases are resistant to the first-line drugs, INH and RIF, XDR-TB cases are resistant to INH, RIF, any fluoroquinolones and, at least one of the three injectable second-line drugs (amikacin, kanamycin, and capreomycin) [104, 105]. The standardized drug susceptibility testing (DST) procedures require eight to 12 weeks to determine drug-resistant Mtb on solid growth media. The DST by automated liquid culture systems is rapid and has better sensitivity than growing bacterial culture on conventional liquid or solid media. However, even with liquid cultures, two to four weeks are needed to obtain DST for suspected MDR/XDR cases.

The MGIT system has replaced the conventional BACTEC 460 TB radiometric system of DST and is currently used in several TB-endemic countries [106]. This method reduced the turn-around time of DST to approximately ten days.

Apart from the liquid-based assays, rapid phenotypic methods, such as growth in tyrosine kinase medium, microscopic observation of drug susceptibility (MODS), and FASTPlaque-Response assays have also been evaluated in MGIT platform, since patient samples can directly be tested in this methods [107]. Despite their technical advancement, these procedures lack reliability and need another confirmatory test for concordant DST results. Recently, WGS is gaining more attention as an option to detect drug-resistant Mtb and for better understanding of the molecular basis of TB transmission in the population. In general, a good correlation exists between Mtb genetic mutations and culture-based DST results in the context of TB treatment [108]. Abbott RealTime MTB RIF/INH Resistance kit was evaluated and found effective in detecting RIF and INH resistance [109]. Several diagnostic kits described above are also evaluated for direct DST using sputum samples. For example, VereMTB kit showed a sensitivity and specificity of $85.7 \%$ and $93.9 \%$, respectively, for RIF resistance detection and $75.0 \%$ and $95.7 \%$, respectively, for INH resistance detection [43].

\section{Molecular biological diagnosis of NTM diseases}

Unlike TB, the methodologies used to diagnose NTM diseases, to discriminate between Mtb and NTM and, to differentiate among NTM species, are complicated and underdeveloped. Rapid differentiation between Mtb and NTM, as well as species identification in the clinical sample, is crucial for effective treatment. A quick Immunochromatographic test (ICT) kit, called SD Bioline TB Ag MPT64 RAPID ${ }^{\circ}$, has been routinely used for the differentiation of Mtb from NTM. The ICT kit detects MPT 64 antigen, present only in Mtb isolates, using 
mouse monoclonal antibody. This assay takes less than 30 minutes, does not require special instrumentation or sample preparation, and has been extensively evaluated for its reliable performance [27, 28]. Another method for NTM species identification is HPLC, in which mycolic acids, a peculiar type of cell wall fatty acids found in mycobacteria, are analyzed. The HPLC method is highly species-specific and has been shown to differentiate 99.5\% of mycobacteria, cultured from clinical specimens, and $95.6 \%$ of NTM species $[29,30]$.

In addition, Plikaytis et al have developed a two-step assay by combining gene amplification and restriction fragment length polymorphism analysis for differentiating among slow-growing mycobacteria. This method can differentiate $>90 \%$ of potentially pathogenic mycobacteria isolates and $>86 \%$ of all strains in clinical specimens, including Mtb, M. bovis, M. avium, $M$. intracellulare, $M$. kansasii, and M. gordonae [32]. A further improvement in this technique showed PCR and PRA for almost 20 NTM strains with the recognizable pattern established for each of them [34].

A PCR-based sequencing technique has become the gold standard for the identification of mycobacterial species. In this method, the gene coding for $16 \mathrm{~S}$ ribosomal RNA, containing both conserved and variable regions, and present in all bacterial species are most commonly targeted for amplification and sequencing [31, 33].

Molecular methods also help in NTM species identification in clinical samples. Accuprobe analysis, which involves nucleic acid hybridization assay that allows rapid identification of Mtb complex, MAC, $M$. intracellulare, M. gordonae, and M. kansasii is one of the most extensively used methods $[37,49]$.

The Anyplex MTB/NTM MDR-TB was also evaluated to differentiate NTMs from the Mtb complex [45]. The EZplex MTBC/NTM kit and VereMTB detection kit described earlier were also evaluated and shown to be useful for detecting NTM species directly from a sputum sample. The sensitivity and specificity of this method were $98.8 \%-100 \%$ for NTM [42, 43]. The Genedia MTB/ NTM Detection Kit is a multiplex real-time PCR assay that targets the IS6110 region of Mtb, and the internal transcribed spacer region and the rpoB gene of NTM. This kit has shown efficient differential detection of NTM in smear-positive cases, but inadequate for smearnegative cases, and hence needs further validation [48].

Also, an INNO-LiPA Mycobacteria assay, targeting the 16S-23S rRNA spacer region, has been developed for the detection of Mycobacterium spp. and identification of members of the Mtb complex and differentiating 15 NTM species, with an accuracy of $99.6 \%[57,58]$. Similarly, the GenoType Mycobacterium CM test is capable of identifying the Mtb complex and an additional 24 NTM species. In comparison, the GenoType Mycobacterium
AS test is capable of identifying an additional 19 NTM species [54, 56].

As mentioned above, the MALDI-TOF/MS has also been used to identify NTM species from clinical specimens. This method is accurate, rapid, and appears cost-effective system; however, sophistication in instrumentation limits the use of this technique for routine use in endemic countries $[60,61]$.

\section{Drug susceptibility testing for NTM diseases}

After the identification of mycobacterial species present in the clinical specimen, it is crucial to determine their drug susceptibility pattern to devise a suitable treatment strategy. Compared to TB, the DST for NTM diseases is difficult and controversial because of inconsistent agreement in results observed between in vitro testing and in vivo clinical outcomes. Pulmonary NTM disease is a common manifestation among the affected individuals, and the most frequently encountered NTM species are subjected to DST by the broth dilution method [110]. Since a combination of antibiotics is used to treat NTM disease, checkerboard assays, or time-kill analysis are preferred to assess the in vitro drug synergy [111, 112]. The availability of DST results, along with diagnosis, is very crucial in developing an ideal treatment strategy for NTM diseases.

\section{Treatment of TB and NTM diseases Treatment of drug-sensitive TB cases}

For efficient management of $\mathrm{TB}$, treatment should be initiated as early as possible in the confirmed as well as suspected cases. Delays in starting treatment have been closely associated with poor clinical outcomes [113, 114]. The currently used anti-TB drugs are classified into: group 1- first-line oral antibiotics, INH, RIF, ETH, and PZA; group 2- injectable second-line medicines (amikacin, kanamycin, and capreomycin plus streptomycin, which is considered first-line, but also an injectable); group 3- fluoroquinolones; group 4- second-line bacteriostatic drugs (ethionamide/prothionamide, paraaminosalicylic acid, and cycloserine/terizidone); and group 5- new or repurposed drugs [115]. The ATS, IDSA and the US-CDC have jointly developed a guideline for the treatment of drug-susceptible TB, which is endorsed by the US National Tuberculosis Controllers Association (NTCA) and the European Respiratory Society (ERS) (Table 2). According to this guideline, the preferred regimen for treating adults with TB caused by organisms that are not known or suspected to be drugresistant should consist of INH, RIF, PZA, and EMB for two months, followed by four months of INH and RIF. In the case of drug susceptibility data available, EMB can be discontinued if the isolate is susceptible to both RIF and INH [116]. For MDR and XDR-TB cases, additional 
Table 2 Description of drugs used in the treatment of adults with TB based on the ATS/ CDC/ IDSA Guidelines

\begin{tabular}{|c|c|c|}
\hline Drug Group & Anti -TB drug & Dosage \\
\hline \multirow[t]{4}{*}{ First-line $^{a}$} & Isoniazid (Oral or IM or IV) & $\begin{array}{l}5 \mathrm{mg} / \mathrm{kg}(\sim 300 \mathrm{mg}) \\
\text { Pyridoxine } 25-50 \mathrm{mg} / \text { day, is given with } \mathrm{INH} \text { to persons } \\
\text { at risk of neuropathy }\end{array}$ \\
\hline & Rifampicin (Oral or IV) & $10 \mathrm{mg} / \mathrm{kg}(\sim 600 \mathrm{mg})$ \\
\hline & $\begin{array}{l}\text { Pyrazinamide } \\
\text { (Oral) }\end{array}$ & $\begin{array}{l}1000 \mathrm{mg} \text { (40 - } 55 \mathrm{~kg} \text { weight) } \\
1500 \mathrm{mg}(56-75 \mathrm{~kg} \text { weight) } \\
2000 \mathrm{mg} \text { (76 - } 90 \mathrm{~kg} \text { weight) }\end{array}$ \\
\hline & $\begin{array}{l}\text { Ethambutol } \\
\text { (Oral) }\end{array}$ & $\begin{array}{l}800 \mathrm{mg}(40-55 \mathrm{~kg} \text { weight }) \\
1200 \mathrm{mg}(56-75 \mathrm{~kg} \text { weight }) \\
1600 \mathrm{mg} \text { (76 - } 90 \mathrm{~kg} \text { weight) }\end{array}$ \\
\hline \multirow[t]{8}{*}{ Second-line ${ }^{a}$} & Cycloserine (Oral) & 10-15 mg/kg (usually 250-500 mg once or twice daily \\
\hline & Ethionamide (Oral) & 10-15 mg/kg (usually 250-500 mg once or twice daily \\
\hline & Streptomycin (IM or IV) & $\begin{array}{l}15 \mathrm{mg} / \mathrm{kg} \text { daily. Some clinicians prefer } 25 \mathrm{mg} / \mathrm{kg} 3 \text { times } \\
\text { weekly or the } 15 \mathrm{mg} / \mathrm{kg} \text { dose } 3 \text { times weekly for patients } \\
\text { with poor renal function }\end{array}$ \\
\hline & $\begin{array}{l}\text { Amikacin/kanamycin } \\
\text { (IM or IV) }\end{array}$ & $\begin{array}{l}15 \mathrm{mg} / \mathrm{kg} \text { daily. Some clinicians prefer } 25 \mathrm{mg} / \mathrm{kg} 3 \text { times } \\
\text { weekly or the } 15 \mathrm{mg} / \mathrm{kg} \text { dose } 3 \text { times weekly for patients } \\
\text { with poor renal function }\end{array}$ \\
\hline & Capreomycin (IM or IV) & $\begin{array}{l}15 \mathrm{mg} / \mathrm{kg} \text { daily. Some clinicians prefer } 25 \mathrm{mg} / \mathrm{kg} 3 \text { times } \\
\text { weekly or the } 15 \mathrm{mg} / \mathrm{kg} \text { dose } 3 \text { times weekly for patients } \\
\text { with poor renal function }\end{array}$ \\
\hline & $\begin{array}{l}\text { Para-amino salicylic acid } \\
\text { (Granules or tablets or IV) }\end{array}$ & $\begin{array}{l}200-300 \mathrm{mg} / \mathrm{kg} \text { total (usually divided } 100 \mathrm{mg} / \mathrm{kg} \text { given } \\
2 \text { to } 3 \text { times daily) }\end{array}$ \\
\hline & Levofloxacin (Oral or IV) & 500-1000 mg daily \\
\hline & Moxifloxacin (Oral or IV) & 400 mg daily \\
\hline \multirow{8}{*}{$\begin{array}{l}\text { Anti-TB drugs with limited data } \\
\text { available on safety and } \\
\text { effectiveness } b\end{array}$} & Bedaquiline (Oral) & $400 \mathrm{mg}$ daily for 14 days followed by $200 \mathrm{mg} 3$ times/wk \\
\hline & Linezolid (Oral or IV) & 600 mg daily \\
\hline & Clofazimine (Oral) & 100 mg daily \\
\hline & Delamanid (Oral) & 100 mg twice daily \\
\hline & Meropenem (IV) & 1,000 mg 3 times/day \\
\hline & Imipenem-cilastatin (IV) & 1,000 mg 3-4 times/day \\
\hline & Clavulanate (Oral or IV) & 250 mg 3 times/day \\
\hline & High-dose isoniazid (Oral or IV) & 15 mg/kg daily \\
\hline
\end{tabular}

Ref ([47] [33] $\left.]^{\mathrm{b}}\right)$ IM Intra-muscular; IV Intravenous. ATS American Thoracic Society; CDC Centres for Disease Control; IDSA Infectious Disease Society of America.

drugs from class- 2 through 5 can be prescribed based on the clinical manifestation of disease and the drugresistance pattern of the bacteria (see below).

\section{Treatment of HIV-TB, TB-DM, and drug-resistant TB cases}

The treatment regimen for patients with HIV-TB have many important considerations, compared to TB cases without HIV. For drug-susceptible pulmonary TB cases with HIV infection, receiving anti-retroviral therapy (ART), the standard TB regimen with two months of INH, RIF, PZA, and EMB followed by four months of INH and RIF, is recommended [117]. In these patients, ART should be started within the first eight weeks of beginning the antiTB treatment and within two weeks in profoundly immunosuppressed HIV-TB patients with a low CD4 cell count $\left(\left(<50\right.\right.$ cells $\left./ \mathrm{mm}^{3}\right)$ [1]. Further, the WHO recommends the use of cotrimoxazole prophylaxis for all HIV- infected people with active $\mathrm{TB}$, regardless of the $\mathrm{CD} 4$ cell counts, to manage co-infections. However, early initiation of ART combined with anti-TB drug results in a condition known as immune reconstitution inflammatory syndrome (IRIS), marked by fever, enlarged lymph nodes, elevated pulmonary infiltrates, and exacerbated inflammatory changes in various internal organs. Usually, IRIS develops in patients within the first three months of ART and is more common when the CD4 cell counts are low $(<50$ cells $/ \mathrm{mm}^{3}$ ). To manage patients with IRIS, antiinflammatory agents, including corticosteroids, are added to the TB and ART therapy [118-120]. In patients with TB-DM, the administration of metformin has been shown to reduce the risk of $\mathrm{TB}$, reduce the mortality during treatment, improve sputum-culture conversion rate, and reduce the relapse rate of TB [79, 121-123]. Additionally, metformin has been considered as a potential adjunctive host- 
directed therapeutic (HDT) agent to treat TB, but this concept warrants more rigorous clinical research to optimize along with TB regimen [124-126].

Although a whole battery of anti-TB drugs is available, the clinical outcome of treatment in different types of pulmonary and extrapulmonary TB is highly variable. Often the therapy achieves an incomplete cure, due to several reasons, including prolonged duration of treatment, drug-induced adverse side effects, patient noncompliance, and the existence of co-morbidities, such as HIV. As a complementary therapeutic modality to antibiotics, a new avenue has been developed, which focusses on host-directed therapy (HDT) for the treatment of TB. This novel concept is based on the modulation of the host response to Mtb infection with small molecules, and used mostly in conjunction with antibiotics, to achieve better and rapid control of TB. The small molecule HDT agents that target autophagy, vitamin D pathway, and anti-inflammatory response are tested in pre-clinical animal models, and several are in phase 2 clinical trials. The case of HDT for TB therapy has been extensively reviewed and published elsewhere recently by several researchers $[124,127,128]$.

Treatment of patients with drug-resistant TB follows a different regimen, based on the resistance pattern of infecting Mtb. For MDR-TB, the WHO recommends a 9 12-month regimen containing seven drugs (gatifloxacin, ETH, PZA, INH, clofazimine, kanamycin, and prothionamide ) during the first four months, followed by four drugs (gatifloxacin, ETH, PZA, and INH) for the next five months [129]. A limitation of this "Bangladesh regimen" is the resistance of bacilli to one or more drugs, making it essential to have additional drug combinations to replace accordingly. With the availability of newer TB drugs, such as bedaquiline, delamanid, pretomanid, and other repurposed drugs, the oral treatment strategy for MDR-TB has been improved [130]. The clinical approach for MDR-TB management incorporates the evidencebased review of the performance of individual medicines used at the recommended doses, with consideration of the balance of benefits versus harms for each drug, the experience of MDR-TB experts on the committee, as well as the perspectives of patients (Table 2). The final choice of drugs and drug classes is also contingent on those considerations, in addition to appropriate monitoring of patients for significant adverse effects, drug-drug interactions, comorbidities, and drug availability.

Similar to MDR-TB, XDR-TB cases are also treated with a combination of available drugs, based on the drug resistance pattern of infecting Mtb. Although conventional MDR-/XDR-TB treatment strategies include surgery as one of the first therapeutic approaches, this strategy has been changed in recent decades, with the invention of several new classes of antibiotics. Apart from the standard anti-TB drugs, there are other drug classes already in clinical use for TB (fluoroquinolones, diarylquinolines, riminophenazines, carbapenems, oxazolidinones, nitroimidazoles), which have been redesigned to optimize bioavailability, potency, safety, or activity against resistant Mtb strains [131]. Besides, new classes of drugs (e.g., inhibitors of Mtb DprE1, leucyl-tRNA synthetase, cholesterol catabolism) with novel mechanisms of action have also been evaluated for MDR/XDR-TB treatment. Several of these compounds are in phase 1 or phase 2 clinical trials and extensively reviewed recently [131]. However, several scientific societies, national and international medical organizations, suggest surgery as adjunctive therapy for MDR/XDR-TB [9].

\section{Treatment of pulmonary NTM diseases}

Unlike the Mtb complex family with few member species, pathogenic NTM is comprised of about 170 species. Each of these NTM species has been identified to have a role in various diseases, including pulmonary disease, lymphadenitis, disseminated diseases, skin, and soft tissue infections [80]. Pulmonary NTM disease is predominantly caused by five of the NTM species (MAC, M. abscessus, M. kansasii, M. xenopi, and M. malmoense), with a different incidence of each of the strains, worldwide [6].. In general, the treatment outcome of pulmonary NTM diseases is highly variable and determined by the host- and pathogen-derived factors, and the nature of the treatment regimen. Despite the use of multiple antibiotics, sputum-conversion, from a positive-to-negative finding of bacteria, is often difficult to achieve in NTM cases, especially those infected with macrolide-resistant NTM species. Resection surgery, in a subgroup of patients with a focal disease or persistent symptoms, has also been considered as adjuvant therapy for severe pulmonary NTM disease [132]. Although NTMs are implicated in many extrapulmonary disease conditions, in this review, we focus on the treatment of pulmonary diseases.

For most patients with nodular or bronchiectatic MAC lung disease, a three-times-weekly regimen containing clarithromycin or azithromycin, ETB, and RIF is recommended as initial therapy (Table 3) $[6,133]$. This intermittent therapeutic approach has the potential advantages of lower medication costs and fewer drug-induced adverse side effects. However, for more severe cavitary disease due to MAC species, the addition of injectable amikacin or streptomycin, along with daily dosing of the above mentioned standard drugs, is preferred $[6,133]$. The clarithromycin-resistant MAC cases with severe disease should be treated with RIF, ETB, and INH or a quinolone (e.g., moxifloxacin), and an injectable aminoglycoside (amikacin or streptomycin). Wherever required, the injectable aminoglycoside therapy is replaced with the nebulized amikacin. Importantly, the 
Table 3 Description of drugs used in the treatment of adults with NTM diseases based on the ATS/IDSA/BTS Guidelines

\begin{tabular}{|c|c|c|}
\hline NTM Species & ATS/IDSA Guidelines ${ }^{a}$ & BTS Guidelines ${ }^{\text {b }}$ \\
\hline M. abscessus & $\begin{array}{l}\text { Minimal surgical resurrection } \\
\text { Macrolide (Clarithromycin 500-1,000 mg/day); } \\
\text { Intravenous amikacin; streptomycin or cefotaxime }\end{array}$ & $\begin{array}{l}\text { Clarithromycin-sensitive or inducible macrolide-resistant isolates } \\
\text { Initial phase: } \geq 1 \text { month } \\
\text { intravenous Amikacin } 15 \mathrm{mg} / \mathrm{kg} \text { daily or } 3 \times \text { per week; intravenous } \\
\text { Tigecycline } 50 \mathrm{mg} \text { twice daily; where tolerated intravenous Imipenem } \\
1 \mathrm{~g} \text { twice daily; where tolerated oral Clarithromycin } 500 \mathrm{mg} \text { twice } \\
\text { daily or oral Azithromycin } 250-500 \mathrm{mg} \text { daily. } \\
\text { Continuation phase: } \\
\text { nebulized Amikacin and oral Clarithromycin } 500 \mathrm{mg} \text { twice daily or } \\
\text { azithromycin } 250-500 \mathrm{mg} \text { daily plus oral clofazimine } 50-100 \mathrm{mg} \text { daily; } \\
\text { oral linezolid } 600 \mathrm{mg} \text { daily or twice daily; oral minocycline } 100 \mathrm{mg} \\
\text { twice daily; oral moxifloxacin } 400 \mathrm{mg} \text { daily; oral cotrimoxazole } 960 \mathrm{mg} \\
\text { twice daily based on the guidance of DST and patient tolerance. } \\
\text { Constitutive macrolide-resistant isolates } \\
\text { Same as above, except Clarithromycin is omitted in both phases. }\end{array}$ \\
\hline
\end{tabular}

\section{MAC \\ (M. avium complex) \\ Non-severe MAC-PD \\ Clarithromycin 1,000 mg or Azithromycin 500 mg, Ethambutol $25 \mathrm{mg} / \mathrm{kg}$, and Rifampin $600 \mathrm{mg}$ administered three times per week Severe MAC-PD \\ Clarithromycin 500-1,000 mg/day; Azithromycin $250 \mathrm{mg} /$ day; Ethambutol $15 \mathrm{mg} / \mathrm{kg} /$ day; Rifampin $10 \mathrm{mg} / \mathrm{kg} /$ day all daily; Intravenous drugs like amikacin or streptomycin}

\section{M. kansasii}

M. malmoense

\section{Rifampicin-sensitive $\boldsymbol{M}$. kansasii-PD}

Rifampin 10 mg/kg/day; Ethambutol 15 g/kg/day; Isoniazid 5 mg/kg/day; Pyridoxine (50 mg/day) Daily

Rifampicin-resistant $\boldsymbol{M}$. kansasii-PD

Three drug regimen - with guidance from DST

Isoniazid; Rifampicin; Ethambutol; With or without Quinolones and Macrolides with guidance from DST (dose not specified)

Isoniazid; Rifabutin or Rifampin; Ethambutol, and Clarithromycin, with or without an initial course of Streptomycin plus inclusion of a Quinolone, preferably moxifloxacin to be substituted for one of the anti-tuberculous drugs

\section{Non-severe MAC-PD}

Rifampicin 600 mg 3 x per week; Ethambutol 25 mg/kg 3xper week; Azithromycin 500 mg $3 \times$ per week or Clarithromycin $1 \mathrm{~g}$ in two divided doses $3 \times$ per week.

\section{Severe MAC-PD}

Rifampicin $600 \mathrm{mg}$ daily; Ethambutol $15 \mathrm{mg} / \mathrm{kg}$ daily; Azithromycin 250 mg daily or Clarithromycin 500 mg twice daily; Intravenous amikacin for up to 3 months or nebulized amikacin

\section{Clarithromycin-resistant MAC PD}

Rifampicin 600 mg daily; Ethambutol 15 mg/kg daily; Isoniazid 300 mg (+pyridoxine $10 \mathrm{mg}$ ) daily or moxifloxacin $400 \mathrm{mg}$ daily Intravenous amikacin for up to 3 months or nebulized amikacin

\section{Rifampicin-sensitive $M$. kansasii-PD}

Rifampicin 600 mg daily; Ethambutol 15 mg/kg daily; Isoniazid 300 mg (with pyridoxine $10 \mathrm{mg}$ ) daily or azithromycin $250 \mathrm{mg}$ daily or clarithromycin 500 mg twice daily.

Rifampicin-resistant $\boldsymbol{M}$. kansasii-PD

Three drug regimen - with guidance from DST

Non-severe $M$. malmoense-PD

Rifampicin $600 \mathrm{mg}$ daily; Ethambutol $15 \mathrm{mg} / \mathrm{kg}$ daily; Azithromycin $250 \mathrm{mg}$ daily or Clarithromycin $500 \mathrm{mg}$ twice daily.

Severe $M$. malmoense-PD

Same as above plus intravenous amikacin for up to 3 months or nebulized amikacin.

\section{Non-severe M. xenopi-PD}

Rifampicin $600 \mathrm{mg}$ daily; Ethambutol $15 \mathrm{mg} / \mathrm{kg}$ daily; Azithromycin 250 mg daily or Clarithromycin 500 mg twice daily; Moxifloxacin $400 \mathrm{mg}$ daily or Isoniazid $300 \mathrm{mg}$ (+pyridoxine $10 \mathrm{mg}$ ) daily

Severe $M$. xenopi-PD

Same as above plus intravenous amikacin for up to 3 months or nebulized amikacin.

Ref $\left([93]^{\mathrm{a}}[87]^{\mathrm{b}}\right)$. PD Pulmonary disease; DST Drug sensitivity testing, ATS American Thoracic Society; IDSA Infectious Disease Society of America; BTS British Thoracic Society.

antibiotic treatment for MAC-pulmonary disease should be continued for a minimum of 12 months after culture conversion [6, 133]. The clofazimine inhalation suspension therapy has been tested in mouse models of M. avium and M. abscessus and proven to be promising, with the drug accumulating at four times more concentration than the oral dosing, in the lungs. This therapy is well tolerated and effective, and now a novel therapeutic candidate for further validation to use in NTM therapy [134].

In contrast to MAC, $M$. abscessus is resistant to all frontline anti-TB drugs, and hence medications of choice are oral macrolides, combined with two parenteral drugs. The ATS/ IDSA guidelines recommend administration of amikacin, cefotaxime, or imipenem for 12 months or till sputum culture conversion [6]. However, $M$. massiliense, one of three subspecies of $M$. abscessus, shows a characteristically different response to clarithromycin, compared to $M$. abscessus. Therefore, precise diagnosis and identification of these species are crucial for the treatment of infected patients [135, 136]. The British Thoracic Society (BTS) guidelines recommend an intravenous injection of amikacin, tigecycline, and imipenem, in addition to an oral macrolide. However, for macrolide-resistant $M$. abscessus, only amikacin, tigecycline, and imipenem are used during the initiation phase (Table 3). Additionally, for both strain types, oral administration of nebulized amikacin, clarithromycin (only for macrolide 
sensitive type), followed by one or more drugs, such as clofazimine, linezolid, minocycline, moxifloxacin, cotrimoxazole is recommended, based on drug susceptibility of the strain and patient tolerance to the drugs (Table 3). Antibiotic treatment for pulmonary diseases caused by $M$. abscessus should be continued for a minimum of 12 months, after specimen culture conversion [133].

Diseases due to $M$. kansasii remains easily treatable since it has similar disease/pathology presentation as pulmonary $\mathrm{TB}$, characterized by fibro-cavitary lesions in the upper lung lobes and usually susceptible to anti-TB drugs with frequent occurrence of RR strains [6]. The ATS/IDSA guidelines recommend a daily regimen of RIF, ETB, INH, and pyridoxine for drug-sensitive M. kansasii; for RR strains, a threedrug regimen, including clarithromycin or azithromycin, moxifloxacin, ethambutol, sulfamethoxazole, or streptomycin is recommended [6]. The BTS guidelines are slightly different from the ATS/IDSA counterpart and suggest to include a macrolide, such as azithromycin or clarithromycin, as an alternative to INH combined with pyridoxine. Treatment of drug-resistant $M$. kansasii strains requires the use of the same three antibiotic therapy, as suggested by ATS/IDSA guidelines [133]. Treatment duration for $M$. kansasii lung diseases should also include 12 months after negative sputum culture result (Table 3).

Most of the infections involving M. malmoense have been associated with pulmonary and lymph node diseases; however, the pulmonary form of the disease is more challenging to treat [6]. The ATS/IDSA guidelines recommend the use of INH, RIF, ETB with and without quinolones and macrolides [6]. The BTS guidelines recommend a minimum of three-drug regimen, including RIF, ETB, and macrolide as a daily treatment for less severe disease. For severe cases, the use of additional injectables, such as amikacin or streptomycin for three months is recommended; however, the injectable can be replaced with the nebulized form of amikacin (Table 3) [133].

Concerning M. xenopi, neither an optimal treatment regimen nor a stipulated duration of treatment has been established. Further, the response of $M$. xenopi to various antibiotics is variable and does not always correlate well with the results of in vitro DST results [6]. A reasonable regimen for $M$. xenopi infection should consist of INH, rifabutin or RIF, ETB, and clarithromycin, with or without an initial course of streptomycin and a quinolone, preferably moxifloxacin, to be substituted for one of the anti-tuberculous drugs. After the initiation of treatment, the sputum conversion occurs readily among $M$. xenopi-infected cases; however, the relapse rates are high even when the regimen contains a macrolide [6]. The BTS guidelines give a choice of four-drug regimen comprising of RIF, ETB, and a macrolide (clarithromycin or azithromycin), with either a quinolone (ciprofloxacin or moxifloxacin) or INH. For severe NTM diseases, injectable or nebulized amikacin is added to the above regimen for up to 3 months (Table 3 ). The BTS guidelines also suggest continuing treatment for up to 12 months after culture conversion [133].

\section{Complications of NTM disease treatment}

The treatment of NTM disease is more complicated and associated with a higher rate of toxicity-related issues compared to TB treatment. The standard, multi-drug therapy used for NTM lung diseases can cause significant adverse effects, which leads to treatment discontinuation and patient non-compliance. Therefore, drug-induced hepatotoxicity, due to rifampin, macrolides, imipenem, or tigecycline, should be carefully monitored, in addition to hematologic disturbances, as assessed by blood cell counts. Further, macrolides can cause ototoxicity or vestibular dysfunction [137]. For efficient management of NTM diseases, these medications should be reviewed periodically, and side effects should be carefully monitored throughout the treatment. The in vitro DST for many NTM does not correlate well with the clinical response of patients to antimycobacterial drugs. Additionally, the procedures for NTM drug susceptibility are limited, compared to TB [6].

Since a significant level of heterogeneity exists in patient response to treatment and that sputum conversion is not reliably achieved in many cases, the medical management of NTM diseases is more complicated than that of TB. Moreover, minimal resection surgery, in a carefully selected subgroup of patients with a focal illness or persistent symptoms, is considered as adjuvant therapy in the treatment of pulmonary NTM infection [132]. Importantly, several new drugs are in the pipeline to improve the treatment of NTM diseases, which include oxazolidinone (Linezolid, Tedizolid, LCB01-0371), inhaled nitric oxide, and amikacin, bedaquiline, beta-lactamase inhibitors such as avibactam, rifabutin, piperidinol-based compound-1, Indole-2-carboxamides and thiacetazone derivatives [10]. These drugs offer the choice and potential for new drug combinations to treat NTM diseases. Recently, many studies are initiated to understand the drug synergy of existing and new drugs at the in vitro (broth culture), inside macrophages, and in the zebrafish model. The information about new drugs, their PK/PD data, and validation in various models have been reviewed recently by Wu ML et al., which would be useful for any new study on NTM drug treatment [10]. Another avenue that has the potential to improve the clinical outcome of NTM therapy and/or to reduce the treatment duration is HDT, which was earlier discussed elaborately for TB $[124,127,128]$. Studies focussing on the repurposing of drugs that can modulate the host response should also help to improve the management of NTM diseases.

As much as rapid diagnosis and better treatment of an infectious disease are crucial, vaccines are very critical to 
contain the spread of infection and, thus, gain global health priority. BCG, a live attenuated strain of M. bovis, is the only vaccine approved by the WHO to prevent $\mathrm{TB}$, mainly in children. At present, BCG is the most widely administered vaccine, with $90 \%$ coverage of the world population [138]. Although BCG is suitable for uninfected people, it cannot provide lifelong immunity and is unsuitable for HIV-infected patients. The development of newer vaccines aims at either a new form of recombinant $\mathrm{BCG}$ ( $\mathrm{rBCG}$ ) or ones that boosts the conventional BCG vaccine. Several potential rBCG/BCG vaccine candidates with novel adjuvants are currently being evaluated for use in TB prevention in clinical studies [139-142]. As previously stated, studies using mouse models have indicated the cross-reactive immunity offered by BCG to pulmonary NTM infections caused by M. avium, M. abscessus, and M. kansasii [82, 143]. Recently, a subunit vaccine (ID91) with the Toll-like receptor agonist glucopyranosyl lipid adjuvant formulated as ID91+GLA-SE indicated protection against $M$. avium in a mouse model [144]. However, unlike TB, the vaccine development pipeline is very poor for NTM infections, concerning the number and complexity of candidate vaccines. Thus, more research focus is needed in this area.

\section{Conclusion}

Recently, the World Health Organization (WHO) has announced an "END-TB strategy" with targets to reduce TB deaths by $95 \%$ and to reduce new cases by $90 \%$ between 2015 and 2035 [73, 145]. However, the emergence of MDR and XDR TB, as well as co-existence of TB with other chronic diseases, pose a significant challenge in achieving this goal. Recent clinical findings have demonstrated the involvement of several NTM species in causing pulmonary diseases, which further contributes to the morbidity and mortality. Since NTMs are also known to have smear positivity and lung involvement very similar to Mtb, diagnosis of NTM in the clinical specimen is often misleading and underestimates the incidence of NTM in many countries. However, the global TB management strategy, including case finding/report, diagnosis, and treatment, are more advanced and better equipped than that available for NTM infections. The currently available tools for the diagnosis, species identification, and DST of NTM are under-developed. Besides, patients with NTM disease are treated with anti-TB drugs, although NTM does not respond well to the standard anti-TB drugs [10].

Nonetheless, a spike in research and clinical activities is noted recently for NTM infections, including the evaluation of a new class of drugs and the exploration of HDT as an alternative or adjunct to antibiotic therapy. These efforts are expected to improve the management of NTM infections globally in the future.

\section{Abbreviations}

TB: Tuberculosis; Mtb: Mycobacterium tuberculosis; NTM: Non-tuberculous mycobacteria; HIV: Human immunodeficiency virus; LTBI: Latent Mtb infection; WHO: World health organization; COPD: Chronic obstructive pulmonary disease; CF: Cystic fibrosis; DM: Diabetes mellitus; INH: Isoniazid; RIF: Rifampicin; PZA: Pyrazinamide; ETH: Ethambutol; MDR: Multidrugresistant; XDR: Extremely drug-resistant; RR: Rifampicin resistant; PNB: P-nitro benzoic acid; ATS: American thoracic society; IDSA: Infectious diseases society of america; AFB: Acid-fast bacilli; FDA: Food and drug administration; NAAT: Nucleic acid amplification test; MTD: Mycobacterium tuberculosis direct; LAMP: Loop-mediated isothermal amplification; CPA: Cross-priming amplification; LiPA: Line probe assay; WGS: Whole genome sequencing; NGS: Next-generation sequencing; MALDI-TOF: Matrix-assisted laser desorption ionization-time of flight; MS: Mass spectrometry; TST: Tuberculin skin test; IGRA: Interferon-gamma release assay; PPD: Purified protein derivative; DST: Drug susceptibility testing; MODS: Microscopic observation of drug susceptibility; HDT: Host directed therapy; HRCT: High resolution computer tomography

\section{Acknowledgments}

Not applicable

\section{Authors' contributions}

Selvakumar Subbian (SS) and RG conceived the concept and designed the manuscript outline. RG, SS, and Sivakumar Shanmugam wrote the manuscript; All authors reviewed, edited the manuscript and agreed for submission. The author(s) read and approved the final manuscript.

\section{Funding}

Not applicable

\section{Availability of data and materials Not applicable}

Ethics approval and consent to participate

Not applicable

\section{Consent for publication}

Not applicable

\section{Competing interests}

The authors declare that they have no competing interests.

\section{Author details}

'Department of Bacteriology, National Institute for Research in Tuberculosis, Chennai, India. ${ }^{2}$ Public Health Research Institute, New Jersey Medical School, Rutgers, The State University of New Jersey, Newark, NJ, United States.

Received: 29 April 2020 Accepted: 5 June 2020

Published online: 17 June 2020

\section{References}

1. WHO. Global tuberculosis report 2019. 2019. https://www.who.int/tb/ publications/global_report/en/. Accessed.

2. Churchyard G, Kim P, Shah NS, Rustomjee R, Gandhi N, Mathema B, Dowdy D, Kasmar A, Cardenas V. What we know about tuberculosis transmission: an overview. J Infect Dis. 2017;216(suppl_6):S629-35.

3. Dheda K, Barry CE 3rd, Maartens G. Tuberculosis. Lancet. 2016;387(10024): 1211-26.

4. Andrews JR, Noubary F, Walensky RP, Cerda R, Losina E, Horsburgh CR. Risk of progression to active tuberculosis following reinfection with Mycobacterium tuberculosis. Clin Infect Dis. 2012;54(6):784-91.

5. Johnson MM, Odell JA. Non-tuberculous mycobacterial pulmonary infections. J Thorac Dis. 2014;6(3):210-20.

6. Griffith DE, Aksamit T, Brown-Elliott BA, Catanzaro A, Daley C, Gordin F, Holland SM, Horsburgh R, Huitt G, lademarco MF, Iseman M, Olivier K, Ruoss S, von Reyn CF, Wallace RJ Jr, Winthrop K, Subcommittee A.T.S.M.D. American Thoracic S. and infectious disease society of A. An official ATS/ IDSA statement: diagnosis, treatment, and prevention of non-tuberculous mycobacterial diseases. Am J Respir Crit Care Med. 2007;175(4):367-416. 
7. Martinez GS, Cano CA, Sota Yoldi LA, Garcia Garcia JM, Alba Alvarez LM, Palacios Gutierrez JJ. en representacion de la Red de Laboratorios de Microbiologia del S. Non-tuberculous mycobacteria. an emerging threat? Arch Bronconeumol. 2017;53(10):554-60.

8. Dheda K, Cox H, Esmail A, Wasserman S, Chang KC, Lange C. Recent controversies about MDR and XDR-TB: Global implementation of the WHO shorter MDR-TB regimen and bedaquiline for all with MDR-TB? Respirology. 2018:23(1):36-45.

9. Nahid P, Mase SR, Migliori GB, Sotgiu G, Bothamley GH, Brozek JL, Cattamanchi A, Cegielski JP, Chen L, Daley CL, Dalton TL, Duarte R, Fregonese F, Horsburgh CR Jr, Ahmad Khan F, Kheir F, Lan Z, Lardizabal A, Lauzardo M, Mangan JM, Marks SM, McKenna L, Menzies D, Mitnick CD, Nilsen DM, Parvez F, Peloquin CA, Raftery A, Schaaf HS, Shah NS, Starke JR, Wilson JW, Wortham JM, Chorba T, Seaworth B. Treatment of drug-resistant tuberculosis. an official ATS/CDC/ERS/IDSA clinical practice guideline. Am J Respir Crit Care Med. 2019;200(10):e93-e142.

10. Wu ML, Aziz DB, Dartois V, Dick T. NTM drug discovery: status, gaps and the way forward. Drug Discov Today. 2018;23(8):1502-19.

11. Chan ED, Iseman MD. Underlying host risk factors for non-tuberculous mycobacterial lung disease. Semin Respir Crit Care Med. 2013;34(1):110-23.

12. Weiss $G$, Schaible UE. Macrophage defense mechanisms against intracellular bacteria. Immunol Rev. 2015;264(1):182-203.

13. Winthrop KL, McNelley E, Kendall B, Marshall-Olson A, Morris C, Cassidy M, Saulson A, Hedberg K. Pulmonary non-tuberculous mycobacterial disease prevalence and clinical features: an emerging public health disease. Am J Respir Crit Care Med. 2010;182(7):977-82.

14. CDC A. Epidemiology of tuberculosis. 2019. https://www.cdc.gov/tb/ education/ssmodules/pdfs/Module2.pdf. Accessed.

15. Falkinham JO 3rd. Epidemiology of infection by non-tuberculous mycobacteria. Clin Microbiol Rev. 1996;9(2):177-215.

16. Hu C, Huang L, Cai M, Wang W, Shi X, Chen W. Characterization of nontuberculous mycobacterial pulmonary disease in Nanjing district of China. BMC Infect Dis. 2019;19(1):764.

17. Jeon CY, Murray MB. Diabetes mellitus increases the risk of active tuberculosis: a systematic review of 13 observational studies. PLoS Med. 2008:5(7):e152

18. Lutfiana NC, van Boven JFM, Masoom Zubair MA, Pena MJ, Alffenaar JC. Diabetes mellitus co-morbidity in patients enrolled in tuberculosis drug efficacy trials around the world: A systematic review. Br J Clin Pharmacol. 2019;85(7):1407-17.

19. Mortaz E, Moloudizargari M, Varahram M, Movassaghi M, Garssen J, Kazempour DM, Mirsaeidi M, Adcock IM. What Immunological Defects Predispose to Non-tuberculosis Mycobacterial Infections? Iran J Allergy Asthma Immunol. 2018;17(2):100-9.

20. Tornheim JA, Dooley KE. Challenges of TB and HIV co-treatment: updates and insights. Curr Opin HIV AIDS. 2018;13(6):486-91.

21. Zhang ZX, Cherng BPZ, Sng LH, Tan YE. Clinical and microbiological characteristics of non-tuberculous mycobacteria diseases in Singapore with a focus on pulmonary disease, 2012-2016. BMC Infect Dis. 2019;19(1):436.

22. Grozdanovic Z, Berrocal Almanza LC, Goyal S, Hussain A, Klassert TE, Driesch D, Tokaryeva V, Loschmann YY, Sumanlatha G, Ahmed N, Valluri V, Schumann RR, Lala B, Slevogt H. A Novel Reading Scheme for Assessing the Extent of Radiographic Abnormalities and Its Association with Disease Severity in Sputum Smear-Positive Tuberculosis: An Observational Study in Hyderabad/India. PLoS One. 2015;10(9):e0138070.

23. Ryu YJ, Koh WJ, Daley CL. Diagnosis and Treatment of Nontuberculous Mycobacterial Lung Disease: Clinicians' Perspectives. Tuberc Respir Dis (Seoul). 2016;79(2):74-84.

24. WHO. Global Tuberculosis Programme. Laboratory services in tuberculosis control. Part II: microscopy. 1998. https:/www.who.int/tb/publications/who_ tb_98_258/en/. Accessed.

25. Caulfield AJ, Wengenack NL. Diagnosis of active tuberculosis disease: From microscopy to molecular techniques. J Clin Tuberc Other Mycobact Dis. 2016:4:33-43.

26. Sharma B, Pal N, Malhotra B, Vyas L. Evaluation of a Rapid Differentiation Test for Mycobacterium Tuberculosis from other Mycobacteria by Selective Inhibition with p-nitrobenzoic Acid using MGIT 960. J Lab Physicians. 2010; 2(2):89-92.

27. Kanade S, Nataraj G, Suryawanshi R, Mehta P. Utility of MPT 64 antigen detection assay for rapid characterization of mycobacteria in a resource constrained setting. Indian J Tuberc. 2012;59(2):92-6.
28. Shenoy VP, Mukhopadhyay C. Rapid Immunochromatographic Test for the Identification and Discrimination of Mycobacterium tuberculosis Complex Isolates from Non-tuberculous Mycobacteria. J Clin Diagn Res. 2014;8(4): DC13-5.

29. Jeong J, Kim SR, Lee SH, Lim JH, Choi Jl, Park JS, Chang CL, Choi JY, Richman DD, Smith DM. The Use of High Performance Liquid Chromatography to Speciate and Characterize the Epidemiology of Mycobacteria. Lab Med. 2011;42(10):612-7.

30. Sebastian G, Nagaraja SB, Vishwanatha T, Voderhobli M, Vijayalakshmi N, Kumar P. Non-Tuberculosis mycobacterium speciation using HPLC under Revised National TB Control Programme (RNTCP) in India. J Appl Microbiol. 2018;124(1):267-73.

31. Kirschner P, Bottger EC. Species identification of mycobacteria using rDNA sequencing. Methods Mol Biol. 1998;101:349-61.

32. Plikaytis BB, Plikaytis BD, Yakrus MA, Butler WR, Woodley CL, Silcox VA, Shinnick TM. Differentiation of slowly growing Mycobacterium species, including Mycobacterium tuberculosis, by gene amplification and restriction fragment length polymorphism analysis. J Clin Microbiol. 1992;30(7):181522.

33. Somoskovi A, Salfinger M. Nontuberculous mycobacteria in respiratory infections: advances in diagnosis and identification. Clin Lab Med. 2014; 34(2):271-95.

34. Telenti A, Marchesi F, Balz M, Bally F, Bottger EC, Bodmer T. Rapid identification of mycobacteria to the species level by polymerase chain reaction and restriction enzyme analysis. J Clin Microbiol. 1993;31(2):175-8.

35. Carpentier E, Drouillard B, Dailloux M, Moinard D, Vallee E, Dutilh B, Maugein J, Bergogne-Berezin E, Carbonnelle B. Diagnosis of tuberculosis by Amplicor Mycobacterium tuberculosis test: a multicenter study. J Clin Microbiol. 1995; 33(12):3106-10.

36. Castan P, de Pablo A, Fernandez-Romero N, Rubio JM, Cobb BD, Mingorance J, Toro C. Point-of-care system for detection of Mycobacterium tuberculosis and rifampin resistance in sputum samples. J Clin Microbiol. 2014;52(2):502-7.

37. Chemlal K, Portaels F. Molecular diagnosis of non-tuberculous mycobacteria. Curr Opin Infect Dis. 2003;16(2):77-83.

38. Dowdy DW, Maters A, Parrish N, Beyrer C, Dorman SE. Cost-effectiveness analysis of the gen-probe amplified mycobacterium tuberculosis direct test as used routinely on smear-positive respiratory specimens. J Clin Microbiol. 2003;41(3):948-53

39. Fang R, Li X, Hu L, You Q, Li J, Wu J, Xu P, Zhong H, Luo Y, Mei J, Gao Q. Cross-priming amplification for rapid detection of Mycobacterium tuberculosis in sputum specimens. J Clin Microbiol. 2009;47(3):845-7.

40. Igarashi Y, Chikamatsu K, Aono A, Yi L, Yamada H, Takaki A, Mitarai S. Laboratory evaluation of the Anyplex II MTB/MDR and MTB/XDR tests based on multiplex real-time PCR and melting-temperature analysis to identify Mycobacterium tuberculosis and drug resistance. Diagn Microbiol Infect Dis. 2017:89(4):276-81.

41. Lawn SD, Nicol MP. Xpert(R) MTB/RIF assay: development, evaluation and implementation of a new rapid molecular diagnostic for tuberculosis and rifampicin resistance. Future Microbiol. 2011;6(9):1067-82.

42. Lee S, Hwang KA, Ahn JH, Nam JH. Evaluation of EZplex MTBC/NTM RealTime PCR kit: diagnostic accuracy and efficacy in vaccination. Clin Exp Vaccine Res. 2018;7(2):111-8.

43. Ou X, Li Q, Su D, Xia H, Wang S, Zhao B, Zhao Y. A pilot study: VereMTB detection kit for rapid detection of multidrug-resistant mycobcterium tuberculosis in clinical sputum samples. PLoS One. 2020;15(3):e0228312.

44. Perez-Garcia F, Ruiz-Serrano MJ, Lopez RP, Acosta F, Perez-Lago L, GarciaDe-Viedma D, Bouza E. Diagnostic performance of Anyplex II MTB/MDR/XDR for detection of resistance to first and second line drugs in Mycobacterium tuberculosis. J Microbiol Methods. 2017;139:74-8.

45. Sali M, De Maio F, Caccuri F, Campilongo F, Sanguinetti M, Fiorentini S, Delogu G, Giagulli C. Multicenter Evaluation of Anyplex Plus MTB/NTM MDR-TB Assay for Rapid Detection of Mycobacterium tuberculosis Complex and Multidrug-Resistant Isolates in Pulmonary and Extrapulmonary Specimens. J Clin Microbiol. 2016;54(1):59-63.

46. Shenai S, Armstrong DT, Valli E, Dolinger DL, Nakiyingi L, Dietze R, Dalcolmo MP, Nicol MP, Zemanay W, Manabe Y, Hadad DJ, Marques-Rodrigues P, Palaci M, Peres RL, Gaeddert M, Armakovitch S, Nonyane BA, Denkinger CM, Banada P, Joloba ML, Ellner J, Boehme C, Alland D, Dorman SE. Analytical and Clinical Evaluation of the Epistem Genedrive Assay for Detection of Mycobacterium tuberculosis. J Clin Microbiol. 2016;54(4):1051-7. 
47. Shete PB, Farr K, Strnad L, Gray CM, Cattamanchi A. Diagnostic accuracy of TB-LAMP for pulmonary tuberculosis: a systematic review and meta-analysis. BMC Infect Dis. 2019;19(1):268.

48. Shin S, Yoo IY, Shim HJ, Kang OK, Jhun BW, Koh WJ, Huh HJ, Lee NY. Diagnostic Performance of the GENEDIA MTB/NTM Detection Kit for Detecting Mycobacterium tuberculosis and Nontuberculous Mycobacteria With Sputum Specimens. Ann Lab Med. 2020;40(2):169-73.

49. Somoskovi A, Mester J, Hale YM, Parsons LM, Salfinger M. Laboratory diagnosis of non-tuberculous mycobacteria. Clin Chest Med. 2002;23(3):58597.

50. WHO. Automated real-time nucleic acid amplification technology for rapid and simultaneous detection of tuberculosis and rifampicin resistance: Xpert MTB/RIF system. Policy statement. 2011. http://apps.who.int/iris/handle/1 0665/44586. Accessed.

51. WHO. Next-generation Xpert ${ }^{\circledR}$ MTB/RIF Ultra assay recommended by WHO 2017.

52. Xu G, Hu L, Zhong H, Wang H, Yusa S, Weiss TC, Romaniuk PJ, Pickerill S, You Q. Cross priming amplification: mechanism and optimization for isothermal DNA amplification. Sci Rep. 2012;2:246.

53. Zhang M, Xue M, He JQ. Diagnostic accuracy of the new Xpert MTB/RIF Ultra for tuberculosis disease: A preliminary systematic review and metaanalysis. Int J Infect Dis. 2020;90:35-45.

54. Makinen J, Marjamaki M, Marttila H, Soini H. Evaluation of a novel strip test, GenoType Mycobacterium CM/AS, for species identification of mycobacterial cultures. Clin Microbiol Infect. 2006;12(5):481-3.

55. Richter E, Weizenegger M, Rusch-Gerdes S, Niemann S. Evaluation of genotype MTBC assay for differentiation of clinical Mycobacterium tuberculosis complex isolates. J Clin Microbiol. 2003;41(6):2672-5.

56. Sarkola A, Makinen J, Marjamaki M, Marttila HJ, Viljanen MK, Soini H. Prospective evaluation of the GenoType assay for routine identification of mycobacteria. Eur J Clin Microbiol Infect Dis. 2004;23(8):642-5.

57. Suffys PN, da Silva RA, de Oliveira M, Campos CE, Barreto AM, Portaels F, Rigouts L, Wouters G, Jannes G, van Reybroeck G, Mijs W, Vanderborght B. Rapid identification of Mycobacteria to the species level using INNO-LiPA Mycobacteria, a reverse hybridization assay. J Clin Microbiol. 2001;39(12):4477-82.

58. Tortoli E, Nanetti A, Piersimoni C, Cichero P, Farina C, Mucignat G, Scarparo C, Bartolini L, Valentini R, Nista D, Gesu G, Tosi CP, Crovatto M, Brusarosco G. Performance assessment of new multiplex probe assay for identification of mycobacteria. J Clin Microbiol. 2001;39(3):1079-84.

59. Doyle RM, Burgess C, Williams R, Gorton R, Booth H, Brown J, Bryant JM, Chan J, Creer D, Holdstock J, Kunst H, Lozewicz S, Platt G, Romero EY, Speight G, Tiberi S, Abubakar I, Lipman M, McHugh TD, Breuer J. Direct whole-genome sequencing of sputum accurately identifies drug-resistant mycobacterium tuberculosis faster than MGIT culture sequencing. J Clin Microbiol. 2018;56(8).

60. Genc GE, Demir M, Yaman G, Kayar B, Koksal F, Satana D. Evaluation of MALDI-TOF MS for identification of non-tuberculous mycobacteria isolated from clinical specimens in mycobacteria growth indicator tube medium. New Microbiol. 2018;41(3):214-9.

61. Mediavilla-Gradolph MC, De Toro-Peinado I, Bermudez-Ruiz MP, GarciaMartinez ML, Ortega-Torres M, Montiel Q-GN, Palop-Borras B. Use of MALDITOF MS for Identification of Nontuberculous Mycobacterium Species Isolated from Clinical Specimens. Biomed Res Int. 2015;2015:854078.

62. Neuschlova M, Vladarova M, Kompanikova J, Sadlonova V, Novakova E. Identification of Mycobacterium Species by MALDI-TOF Mass Spectrometry. Adv Exp Med Biol. 2017;1021:37-42.

63. Nimmo C, Doyle R, Burgess C, Williams R, Gorton R, McHugh TD, Brown M, Morris-Jones $\mathrm{S}$, Booth $\mathrm{H}$, Breuer J. Rapid identification of a Mycobacterium tuberculosis full genetic drug resistance profile through whole genome sequencing directly from sputum. Int J Infect Dis. 2017;62:44-6.

64. Nurwidya F, Handayani D, Burhan E, Yunus F. Molecular Diagnosis of Tuberculosis. Chonnam Med J. 2018;54(1):1-9.

65. Witney AA, Cosgrove CA, Arnold A, Hinds J, Stoker NG, Butcher PD. Clinical use of whole genome sequencing for Mycobacterium tuberculosis. BMC Med. 2016;14:46

66. Zakham F, Laurent S, Esteves Carreira AL, Corbaz A, Bertelli C, Masserey E, Nicod L, Greub G, Jaton K, Mazza-Stalder J, Opota O. Whole-genome sequencing for rapid, reliable and routine investigation of Mycobacterium tuberculosis transmission in local communities. New Microbes New Infect. 2019;31:100582.

67. Haas MK, Belknap RW. Diagnostic Tests for Latent Tuberculosis Infection. Clin Chest Med. 2019;40(4):829-37.
68. Lewinsohn DM, Leonard MK, LoBue PA, Cohn DL, Daley CL, Desmond E, Keane J, Lewinsohn DA, Loeffler AM, Mazurek GH, O'Brien RJ, Pai M, Richeldi L, Salfinger M, Shinnick TM, Sterling TR, Warshauer DM, Woods GL. Official American Thoracic Society/Infectious Diseases Society of America/Centers for Disease Control and Prevention Clinical Practice Guidelines: Diagnosis of Tuberculosis in Adults and Children. Clin Infect Dis. 2017;64(2):e1-e33.

69. Mazurek GH, Jereb J, Vernon A, LoBue P, Goldberg S, Castro K, Committee IE. Centers for disease C. and prevention. updated guidelines for using interferon gamma release assays to detect mycobacterium tuberculosis infection - United States, 2010. MMWR Recomm Rep. 2010;59(RR-5):1-25

70. Theel ES, Hilgart H, Breen-Lyles M, McCoy K, Flury R, Breeher LE, Wilson J, Sia IG, Whitaker JA, Clain J, Aksamit TR, Escalante P. Comparison of the QuantiFERON-TB Gold Plus and QuantiFERON-TB Gold In-Tube interferon gamma release assays in patients at risk for tuberculosis and in health care workers. J Clin Microbiol. 2018;56(7):e00614-8.

71. Mitchison D, Davies G. The chemotherapy of tuberculosis: past, present and future. Int J Tuberc Lung Dis. 2012;16(6):724-32.

72. Dean AS, Cox H, Zignol M. Epidemiology of Drug-Resistant Tuberculosis. Adv Exp Med Biol. 2017;1019:209-20.

73. WHO. End TB Strategy. 2015:2015.

74. Bryant JM, Grogono DM, Rodriguez-Rincon D, Everall I, Brown KP, Moreno P, Verma D, Hill E, Drijkoningen J, Gilligan P, Esther CR, Noone PG, Giddings O, Bell SC, Thomson R, Wainwright CE, Coulter C, Pandey S, Wood ME, Stockwell RE, Ramsay KA, Sherrard LJ, Kidd TJ, Jabbour N, Johnson GR, Knibbs LD, Morawska L, Sly PD, Jones A, Bilton D, Laurenson I, Ruddy M, Bourke S, Bowler IC, Chapman SJ, Clayton A, Cullen M, Daniels T, Dempsey O, Denton M, Desai M, Drew RJ, Edenborough F, Evans J, Folb J, Humphrey $\mathrm{H}$, Isalska B, Jensen-Fangel S, Jonsson B, Jones AM, Katzenstein TL, Lillebaek T, MacGregor G, Mayell S, Millar M, Modha D, Nash EF, O'Brien C, O'Brien D, Ohri C, Pao CS, Peckham D, Perrin F, Perry A, Pressler T, Prtak L, Qvist T, Robb A, Rodgers H, Schaffer K, Shafi N, van Ingen J, Walshaw M, Watson D, West N, Whitehouse J, Haworth CS, Harris SR, Ordway D, Parkhill J, Floto RA. Emergence and spread of a human-transmissible multidrug-resistant nontuberculous mycobacterium. Science. 2016;354(6313):751-7.

75. Wolinsky E. Nontuberculous mycobacteria and associated diseases. Am Rev Respir Dis. 1979;119(1):107-59.

76. Hoza AS, Mfinanga SG, Rodloff AC, Moser I, Konig B. Increased isolation of nontuberculous mycobacteria among TB suspects in Northeastern, Tanzania: public health and diagnostic implications for control programmes. BMC Res Notes. 2016;9: 109.

77. Jain S, Sankar MM, Sharma N, Singh S, Chugh TD. High prevalence of nontuberculous mycobacterial disease among non-HIV infected individuals in a TB-endemic country--experience from a tertiary center in Delhi, India. Pathog Glob Health. 2014;108(2):118-22.

78. Hoefsloot W, van Ingen J, Andrejak C, Angeby K, Bauriaud R, Bemer P, Beylis N, Boeree MJ, Cacho J, Chihota V, Chimara E, Churchyard G, Cias R, Daza R, Daley CL, Dekhuijzen PN, Domingo D, Drobniewski F, Esteban J, FauvilleDufaux M, Folkvardsen DB, Gibbons N, Gomez-Mampaso E, Gonzalez R, Hoffmann $H$, Hsueh PR, Indra A, Jagielski $T$, Jamieson $F$, Jankovic $M$, Jong $E$, Keane J, Koh WJ, Lange B, Leao S, Macedo R, Mannsaker T, Marras TK, Maugein J, Milburn HJ, Mlinko T, Morcillo N, Morimoto K, Papaventsis D, Palenque E, Paez-Pena M, Piersimoni C, Polanova M, Rastogi N, Richter E, Ruiz-Serrano MJ, Silva A, da Silva MP, Simsek H, van Soolingen D, Szabo N, Thomson R, Tortola Fernandez T, Tortoli E, Totten SE, Tyrrell G, Vasankari T, Villar M, Walkiewicz R, Winthrop KL, Wagner D, Nontuberculous Mycobacteria Network European Trials G. The geographic diversity of nontuberculous mycobacteria isolated from pulmonary samples: an NTM-NET collaborative study. Eur Respir J. 2013;42(6):1604-13.

79. Degner NR, Wang JY, Golub JE, Karakousis PC. Metformin Use Reverses the Increased Mortality Associated With Diabetes Mellitus During Tuberculosis Treatment. Clin Infect Dis. 2018;66(2):198-205.

80. Baldwin SL, Larsen SE, Ordway D, Cassell G, Coler RN. The complexities and challenges of preventing and treating non-tuberculous mycobacterial diseases. PLoS Negl Trop Dis. 2019;13(2):e0007083.

81. Marras TK, Chedore P, Ying AM, Jamieson F. Isolation prevalence of pulmonary non-tuberculous mycobacteria in Ontario, 1997 2003. Thorax. 2007;62(8):661-6.

82. Abate G, Hamzabegovic F, Eickhoff CS, Hoft DF. BCG Vaccination Induces M. avium and M. abscessus Cross-Protective Immunity. Front Immunol. 2019;10:234.

83. Ahn CH, Lowell JR, Onstad GD, Shuford EH, Hurst GA. A demographic study of disease due to Mycobacterium kansasii or M intracellulare-avium in Texas. Chest. 1979;75(2):120-5. 
84. Kontturi A, Soini H, Ollgren J, Salo E. Increase in Childhood Nontuberculous Mycobacterial Infections After Bacille Calmette-Guerin Coverage Drop: A Nationwide, Population-Based Retrospective Study, Finland, 1995-2016. Clin Infect Dis. 2018;67(8):1256-61.

85. Trnka L, Dankova D, Svandova E. Six years' experience with the discontinuation of BCG vaccination. 4. Protective effect of BCG vaccination against the Mycobacterium avium intracellulare complex. Tuber Lung Dis. 1994;75(5):348-52.

86. Prevots DR, Shaw PA, Strickland D, Jackson LA, Raebel MA, Blosky MA, Montes de Oca R, Shea YR, Seitz AE, Holland SM, Olivier KN. Nontuberculous mycobacterial lung disease prevalence at four integrated health care delivery systems. Am J Respir Crit Care Med. 2010;182(7):970-6.

87. Lai CC, Tan CK, Chou CH, Hsu HL, Liao CH, Huang YT, Yang PC, Luh KT, Hsueh PR. Increasing incidence of non-tuberculous mycobacteria, Taiwan, 2000-2008. Emerg Infect Dis. 2010;16(2):294-6.

88. Lai CC, Tan CK, Lin SH, Liu WL, Liao CH, Huang YT, Hsueh PR. Clinical significance of non-tuberculous mycobacteria isolates in elderly Taiwanese patients. Eur J Clin Microbiol Infect Dis. 2011;30(6):779-83.

89. Moore JE, Kruijshaar ME, Ormerod LP, Drobniewski F, Abubakar I. Increasing reports of non-tuberculous mycobacteria in England, Wales and Northern Ireland, 1995-2006. BMC Public Health. 2010;10:612.

90. Ayelign B, Negash M, Genetu M, Wondmagegn T, Shibabaw T. Immunological Impacts of Diabetes on the Susceptibility of Mycobacterium tuberculosis. J Immunol Res. 2019;2019:6196532.

91. Baker MA, Harries AD, Jeon CY, Hart JE, Kapur A, Lonnroth K, Ottmani SE, Goonesekera SD, Murray MB. The impact of diabetes on tuberculosis treatment outcomes: a systematic review. BMC Med. 2011;9:81.

92. Kumar NP, Babu S. Influence of diabetes mellitus on immunity to human tuberculosis. Immunology. 2017;152(1):13-24.

93. Bridson T, Govan B, Ketheesan N, Norton R. Overrepresentation of Diabetes in Soft Tissue Nontuberculous Mycobacterial Infections. Am J Trop Med Hyg. 2016;95(3):528-30.

94. Pande T, Pai M, Denkinger C. Use of Chest X-rays in 22 High Tuberculosis Burden Countries. CHEST. 2015;148(4):141A

95. Centers for Disease C. and Prevention. Updated guidelines for the use of nucleic acid amplification tests in the diagnosis of tuberculosis. MMWR Morb Mortal Wkly Rep. 2009;58(1):7-10.

96. Leonard MK, Osterholt D, Kourbatova EV, Del Rio C, Wang W, Blumberg HM. How many sputum specimens are necessary to diagnose pulmonary tuberculosis? Am J Infect Control. 2005:33(1):58-61.

97. Phillips PPJ, Mendel CM, Nunn AJ, McHugh TD, Crook AM, Hunt R, Bateson A, Gillespie SH. A comparison of liquid and solid culture for determining relapse and durable cure in phase III TB trials for new regimens. BMC Med. 2017;15(1):207.

98. Catanzaro A. Diagnosis, differentiating colonization, infection, and disease. Clin Chest Med. 2002;23(3):599-601, vi.

99. Scohy A, Gohy S, Mathys V, Sapriel G, Toussaint L, Bressant F, Zitouni A, Teylaert MN, Vander Meeren MC, Colmant A, Simon A, Perry JD, Lebecque $P$, Andre E. Comparison of the RGM medium and the mycobacterial growth indicator tube automated system for isolation of non-tuberculous mycobacteria from sputum samples of cystic fibrosis patients in Belgium. J Clin Tuberc Other Mycobact Dis. 2018;13:1-4.

100. Stephenson D, Perry A, Appleby MR, Lee D, Davison J, Johnston A, Jones AL, Nelson A, Bourke SJ, Thomas MF, De Soyza A, Lordan JL, Lumb J, Robb $A E$, Samuel JR, Walton KE, Perry JD. An evaluation of methods for the isolation of non-tuberculous mycobacteria from patients with cystic fibrosis, bronchiectasis and patients assessed for lung transplantation. BMC Pulm Med. 2019;19(1):19.

101. Bhalla GS, Sarao MS, Kalra D, Bandyopadhyay K, John AR. Methods of phenotypic identification of non-tuberculous mycobacteria. Pract Lab Med. 2018;12:e00107.

102. Moore DF, Guzman JA, Mikhail LT. Reduction in turn-around time for laboratory diagnosis of pulmonary tuberculosis by routine use of a nucleic acid amplification test. Diagn Microbiol Infect Dis. 2005;52(3):247-54.

103. Guerra RL, Hooper NM, Baker JF, Alborz R, Armstrong DT, Maltas G, Kiehlbauch JA, Dorman SE. Use of the amplified mycobacterium tuberculosis direct test in a public health laboratory: test performance and impact on clinical care. Chest. 2007;132(3):946-51.

104. Shah NS, Wright A, Bai GH, Barrera L, Boulahbal F, Martin-Casabona N, Drobniewski F, Gilpin C, Havelkova M, Lepe R, Lumb R, Metchock B, Portaels F, Rodrigues MF, Rusch-Gerdes S, Van Deun A, Vincent V, Laserson K, Wells
C, Cegielski JP. Worldwide emergence of extensively drug-resistant tuberculosis. Emerg Infect Dis. 2007;13(3):380-7.

105. Zignol M, Hosseini MS, Wright A, Weezenbeek CL, Nunn P, Watt CJ, Williams BG, Dye C. Global incidence of multidrug-resistant tuberculosis. J Infect Dis. 2006;194(4):479-85.

106. Rusch-Gerdes S, Pfyffer GE, Casal M, Chadwick M, Siddiqi S. Multicenter laboratory validation of the BACTEC MGIT 960 technique for testing susceptibilities of Mycobacterium tuberculosis to classical second-line drugs and newer antimicrobials. J Clin Microbiol. 2006;44(3):688-92.

107. Pai M, Kalantri S, Dheda K. New tools and emerging technologies for the diagnosis of tuberculosis: part II. Active tuberculosis and drug resistance. Expert Rev Mol Diagn. 2006;6(3):423-32.

108. Shanmugam S, Kumar N, Nair D, Natrajan M, Tripathy SP, Peacock SJ, Swaminathan S, Ranganathan UD. Genome sequencing of polydrug-, multidrug-, and extensively drug-resistant mycobacterium tuberculosis strains from South India. Microbiol Resour Announc. 2019;8(12):e01388-18.

109. Kostera J, Leckie G, Abravaya K, Wang H. Performance of the Abbott RealTime MTB RIF/INH resistance assay when used to test Mycobacterium tuberculosis specimens from Bangladesh. Infect Drug Resist. 2018;11:695-9.

110. van Ingen J, Kuijper EJ. Drug susceptibility testing of non-tuberculous mycobacteria. Future Microbiol. 2014;9(9):1095-110.

111. Huang CW, Chen JH, Hu ST, Huang WC, Lee YC, Huang CC, Shen GH. Synergistic activities of tigecycline with clarithromycin or amikacin against rapidly growing mycobacteria in Taiwan. Int J Antimicrob Agents. 2013; 41(3):218-23.

112. Kaushik A, Makkar N, Pandey P, Parrish N, Singh U, Lamichhane G. Carbapenems and Rifampin Exhibit Synergy against Mycobacterium tuberculosis and Mycobacterium abscessus. Antimicrob Agents Chemother. 2015;59(10):6561-7.

113. Htwe KK, Kyaw NTT, Kumar AMV, Kyaw KWY, Oo MM, Thwin T, Saw S, Aung ST. Pre-treatment loss to follow-up and treatment delay among bacteriologically-confirmed tuberculosis patients diagnosed in Mandalay Region. Myanmar. Trop Med Health. 2019;47:30.

114. Virenfeldt J, Rudolf F, Camara C, Furtado A, Gomes V, Aaby P, Petersen E, Wejse C. Treatment delay affects clinical severity of tuberculosis: a longitudinal cohort study. BMJ Open. 2014;4(6):e004818.

115. Caminero JA, Scardigli A. Classification of antituberculosis drugs: a new proposal based on the most recent evidence. Eur Respir J. 2015;46(4):88793.

116. Nahid P, Dorman SE, Alipanah N, Barry PM, Brozek JL, Cattamanchi A, Chaisson LH, Chaisson RE, Daley CL, Grzemska M, Higashi JM, Ho CS, Hopewell PC, Keshavjee SA, Lienhardt C, Menzies R, Merrifield C, Narita M, O'Brien R, Peloquin CA, Raftery A, Saukkonen J, Schaaf HS, Sotgiu G, Starke $J R$, Migliori GB, Vernon A. Official American thoracic society/centers for disease control and prevention/infectious diseases society of America clinical practice guidelines: treatment of drug-susceptible tuberculosis. Clin Infect Dis. 2016;63(7):e147-95.

117. Zha BS, Nahid P. Treatment of Drug-Susceptible Tuberculosis. Clin Chest Med. 2019:40(4):763-74.

118. Meintjes G, Scriven J, Marais S. Management of the immune reconstitution inflammatory syndrome. Curr HIV/AIDS Rep. 2012;9(3):238-50.

119. Walker NF, Stek C, Wasserman S, Wilkinson RJ, Meintjes G. The tuberculosisassociated immune reconstitution inflammatory syndrome: recent advances in clinical and pathogenesis research. Curr Opin HIV AIDS. 2018;13(6):512-21.

120. WHO. Guidelines on Post-Exposure Prophylaxis for HIV and the Use of CoTrimoxazole Prophylaxis for HIV-Related Infections Among Adults, Adolescents and Children: Recommendations for a Public Health Approach: December 2014 supplement to the 2013 consolidated guidelines on the use of anti-retroviral drugs for treating and preventing HIV infection. Geneva: WHO press; 2014.

121. Lee YJ, Han SK, Park JH, Lee JK, Kim DK, Chung HS, Heo EY. The effect of metformin on culture conversion in tuberculosis patients with diabetes mellitus. Korean J Intern Med. 2018;33(5):933-40.

122. Ma Y, Pang Y, Shu W, Liu YH, Ge QP, Du J, Li L, Gao WW. Metformin reduces the relapse rate of tuberculosis patients with diabetes mellitus: experiences from 3-year follow-up. Eur J Clin Microbiol Infect Dis. 2018;37(7):1259-63.

123. Yu X, Li L, Xia L, Feng X, Chen F, Cao S, Wei X. Impact of metformin on the risk and treatment outcomes of tuberculosis in diabetics: a systematic review. BMC Infect Dis. 2019;19(1):859.

124. Kolloli A, Subbian S. Host-Directed Therapeutic Strategies for Tuberculosis. Front Med (Lausanne). 2017:4:171. 
125. Naicker N, Sigal A, Naidoo K. Metformin as Host-Directed Therapy for TB Treatment: Scoping Review. Front Microbiol. 2020;11:435.

126. Yew WW, Chang KC, Chan DP, Zhang Y. Metformin as a host-directed therapeutic in tuberculosis: Is there a promise? Tuberculosis (Edinb). 2019; 115:76-80.

127. Baindara P. Host-directed therapies to combat tuberculosis and associated non-communicable diseases. Microb Pathog. 2019;130:156-68.

128. Young C, Walzl G, Du Plessis N. Therapeutic host-directed strategies to improve outcome in tuberculosis. Mucosal Immunol. 2019.

129. Van Deun A, Maug AK, Salim MA, Das PK, Sarker MR, Daru P, Rieder HL. Short, highly effective, and inexpensive standardized treatment of multidrug-resistant tuberculosis. Am J Respir Crit Care Med. 2010;182(5):68492.

130. WHO. Technical report on critical concentrations for TB drug susceptibility testing of medicines used in the treatment of drug-resistant TB. 2018. https://www.who.int/tb/publications/2018/WHO_technical_report_ concentrations_TB_drug_susceptibility/en/. Accessed.

131. Ignatius EH, Dooley KE. New Drugs for the Treatment of Tuberculosis. Clin Chest Med. 2019;40(4):811-27.

132. Lu M, Fitzgerald D, Karpelowsky J, Selvadurai H, Pandit C, Robinson P, Marais BJ. Surgery in non-tuberculous mycobacteria pulmonary disease. Breathe (Sheff). 2018;14(4):288-301.

133. Haworth CS, Banks J, Capstick T, Fisher AJ, Gorsuch T, Laurenson IF, Leitch A, Loebinger MR, Milburn HJ, Nightingale M, Ormerod P, Shingadia D, Smith D, Whitehead N, Wilson R, Floto RA. British Thoracic Society guidelines for the management of non-tuberculous mycobacterial pulmonary disease (NTMPD). Thorax. 2017;72(Suppl 2):ii1-ii64.

134. Banaschewski B, Verma D, Pennings LJ, Zimmerman M, Ye Q, Gadawa J, Dartois V, Ordway D, van Ingen J, Ufer S, Stapleton K, Hofmann T. Clofazimine inhalation suspension for the aerosol treatment of pulmonary non-tuberculous mycobacterial infections. J Cyst Fibros. 2019;18(5):714-20.

135. Kim HY, Kim BJ, Kook Y, Yun YJ, Shin JH, Kim BJ, Kook YH. Mycobacterium massiliense is differentiated from Mycobacterium abscessus and Mycobacterium bolletii by erythromycin ribosome methyltransferase gene (erm) and clarithromycin susceptibility patterns. Microbiol Immunol. 2010; 54(6):347-53.

136. Koh WJ, Jeon K, Lee NY, Kim BJ, Kook YH, Lee SH, Park YK, Kim CK, Shin SJ, Huitt GA, Daley CL, Kwon OJ. Clinical significance of differentiation of Mycobacterium massiliense from Mycobacterium abscessus. Am J Respir Crit Care Med. 2011;183(3):405-10.

137. Egelund EF, Fennelly KP, Peloquin CA. Medications and monitoring in nontuberculous mycobacteria infections. Clin Chest Med. 2015;36(1):55-66.

138. Luca S, Mihaescu T. History of BCG Vaccine. Maedica (Buchar). 2013;8(1):538.

139. Hatherill M, Tait D, McShane H. Clinical testing of tuberculosis vaccine candidates. Microbiol Spectr. 2016;4(5):TBTB2-0015-2016.

140. Kaufmann SHE. Vaccination Against Tuberculosis: Revamping BCG by Molecular Genetics Guided by Immunology. Front Immunol. 2020;11:316.

141. Li J, Zhao A, Tang J, Wang G, Shi Y, Zhan L, Qin C. Tuberculosis vaccine development: from classic to clinical candidates. Eur J Clin Microbiol Infect Dis. 2020.

142. Sable SB, Posey JE, Scriba TJ. Tuberculosis vaccine development: progress in clinical evaluation. Clin Microbiol Rev. 2019;33(1):00100-19.

143. Orme IM, Collins FM. Prophylactic effect in mice of BCG vaccination against non-tuberculous mycobacterial infections. Tubercle. 1985;66(2):117-20.

144. Larsen SE, Reese VA, Pecor TI, Brewer G, Berube B, Njikan S, Parish T, HenaoTamayo M, Baldwin SL, Coler RN. Subunit vaccine candidate with adjuvant confers protection against clinical Mycobacterium avium in wild type and immunocompromised mouse models. J Immunol. 2019;202(1):139.135.

145. Matteelli A, Sulis G, Capone S, D'Ambrosio L, Migliori GB, Getahun H. Tuberculosis elimination and the challenge of latent tuberculosis. Presse Med. 2017:46(2 Pt 2):e13-21.

\section{Publisher's Note}

Springer Nature remains neutral with regard to jurisdictional claims in published maps and institutional affiliations.

\section{Ready to submit your research? Choose BMC and benefit from}

- fast, convenient online submission

- thorough peer review by experienced researchers in your field

- rapid publication on acceptance

- support for research data, including large and complex data types

- gold Open Access which fosters wider collaboration and increased citations

- maximum visibility for your research: over $100 \mathrm{M}$ website views per year

At BMC, research is always in progress.

Learn more biomedcentral.com/submissions 